\title{
Catalytic Conversion of Lignin in an Isopropanol/formic Acid Medium With Nimo Catalyst Promoted by W Species
}

\section{Xinyu Lu}

Nanjing Forestry University

Hossain Mahmud Robin

Nanjing Forestry University

Haoquan Guo

Nanjing Forestry University

Dandan Wang

Nanjing Forestry University

\section{Pengcheng Xiu}

Nanjing Forestry University

Jiajia Chen

Nanjing Forestry University

Yu Qin

Nanjing Forestry University

Chaozhong Xu

Nanjing Forestry University

Xiaoli Gu ( $\square$ guxiaoli@njfu.edu.cn )

Nanjing Forestry University https://orcid.org/0000-0001-8588-0358

\section{Research Article}

Keywords: Lignin, Formic acid, NiMo catalyst, HDO, Alkyl guaiacols

Posted Date: May 27th, 2021

DOI: https://doi.org/10.21203/rs.3.rs-533979/v1

License: (c) (1) This work is licensed under a Creative Commons Attribution 4.0 International License.

Read Full License 
1 Catalytic conversion of lignin in an isopropanol/formic acid medium 1 with NiMo catalyst promoted by W species

Xinyu Lu, Hossain Mahmud Robin, Haoquan Guo, Dandan Wang, Pengcheng Xiu, Jiajia Chen, Yu Qin, Chaozhong Xu *, Xiaoli Gu* Co-Innovation Center for Efficient Processing and Utilization of Forest Products, College of Chemical Engineering, Nanjing Forestry University, 159 Longpan Road, Nanjing, 210037, P. R. China

*E-mail: xucz@njfu.edu.cn; guxiaoli@njfu.edu.cn

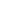

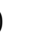




\section{Abstract}

Background: Large amounts of enzymatic hydrolysis lignin (EHL) are generated with the production of cellulosic bioethanol. Efficient degradation and upgrading of EHL is significant for the sustainable and stable development of energy supply.

Results: In this study, hydrodeoxygenation (HDO) of EHL to biofuels was carried out promoted by the in situ hydrogen donor produced from the decomposition of formic acid over NiMo catalysts. Results showed that active sites (derived from the support $\mathrm{SiO}_{2}, \mathrm{~W}$, and NiMo species) had remarkable effect on lignin conversion, and the highest oil yield (57.2 wt\%) was gained over $\mathrm{NiMo} / \mathrm{W}-\mathrm{SiO}_{2}$ catalyst.

Conclusions: The product evolution demonstrated that active metal sites (derived from NiMo species) favored hydrogenolysis and deoxygenation via leading in situ hydrogen to attack C-O-C bonds, while acid sites (derived from the support) adsorbed and activated chemical bonds in lignin, resulting in the linkage cleavage caused by the heating program. The obtained bio-oil was rich in alkyl guaiacols $(6.7 \mathrm{wt} \%)$, containing stable chemical properties and high quality.

Keywords: Lignin; Formic acid; NiMo catalyst; HDO; Alkyl guaiacols 


\section{Background}

Nowadays, fossil-derived resources are the primary source of energy and commercial chemicals in human life. Therefore, the exploration of their substitutes has become a hotspot, especially for the development of bioenergy derived from biomass materials due to their low cost and broad distribution [1-3]. Lignocellulosic biomass, an abundant type of biomass, has drawn considerable attention due to its potential for liquid biofuels and valuable chemicals production [4]. Lignocellulosic biomass consists of three main components, namely cellulose (30-35\%), hemicellulose (20-35\%), and lignin (15$20 \%$ ) [5]. Among them, cellulose and hemicellulose can be effectively converted to gasoline, jet fuels, and diesel range hydrocarbons [6]. Lignin, a naturally aromatic polymer composed of three phenylpropane units (e.g., coniferyl, para-coumaryl, and sinapyl alcohols) which are cross-linked via various bonds (including $\beta$-O-4, $\alpha-\mathrm{O}-4,4-$ O-5, $\beta-\beta, \beta-1$, and 5-5 bonds), can be a prospective resource of aromatic compounds (which are normally obtained from fossil-derived feed stocks). However, these aromatic compounds produced from lignin thermochemical treatment usually contain oxygen, which lowers their quality and limits their further application. Therefore, the elimination of oxygen in lignin-derived compounds is a challenge. At present, hydrodeoxygenation (HDO), using molecular hydrogen over a suitable catalyst, is an efficient hydrotreatment process to produce high-quality biofuels through effective lignin conversion and oxygen elimination.

During cellulosic bioethanol process, a large amount of residue rich in lignin, which is named as enzymatic hydrolysis lignin (EHL), is produced. Recently, the 
pathway of EHL to biofuels is an attractive method to achieve its valuable application [7]. HDO is one of the most effective methods to degrade biomass to biofuels [8]. During HDO, most oxygen-containing components and unsaturated chemical bonds will be converted into saturated hydrocarbons. Therefore, biofuels rich in hydrocarbons can be obtained after HDO process, which have more stable chemical properties and higher energy density. However, the traditional HDO process will consume large amounts of hydrogen, which is expensive and unsafe. Therefore, the utilization of internal hydrogen donors, known as in situ HDO process, is introduced into lignin conversion process [9, 10]. For instance, Li et al. reported the in situ HDO of enzymolysis lignin over NiMo based catalysts using aluminum-water reactions as in situ hydrogen donor, results illustrated that the yield of aromatic hydrocarbons in biofuels increased after in situ $\mathrm{HDO}$ process over $\mathrm{NiMoS} / \mathrm{Al}_{2} \mathrm{O}_{3}$ catalyst [11].

At present, most of in situ hydrogen donors are organic solvents, such as formic acid and alcohols. Furthermore, nickel-molybdenum (NiMo) based catalysts, a promising candidate for hydrotreatment process, have been widely investigated on the conversion of lignin and upgrading of lignin-derived oils. For example, Priharto et al. reported a HDO treatment of lignin-derived bio-oils over NiMo catalysts, and results showed that with assistance of high-pressure molecular hydrogen, the content of oxygen was reduced from $23 \mathrm{wt} \%$ in raw oil to $7.5-11.5 \mathrm{wt} \%$ in hydrotreated oil after HDO [12]. Moreover, numerous studies also focused on the HDO of lignin-derived model compounds, such as guaiacol, phenol, and acetophenone [4, 13-15]. Therefore, the investigation of in situ HDO of raw lignin and internal reaction mechanism is 
meaningful and beneficial for the development of biofuels and bioenergy.

In this experiment, to explore the in situ HDO process of EHL with assistance of formic acid performed as internal hydrogen donor over NiMo catalysts, and to further study the effect of $\mathrm{W}$ species incorporation on lignin depolymerization, a functional $\mathrm{SiO}_{2}$ was prepared to be used as the support of NiMo catalysts which were utilized in EHL depolymerization. Comprehensive characterization was conducted to evaluate the physical and chemical properties of synthesized supports and NiMo catalysts, and to figure out the internal reaction mechanism of lignin depolymerization.

\section{Results}

\section{Catalyst characterization}

Fig. $1 \mathrm{~N}_{2}$ adsorption-desorption isotherms of $\mathrm{SiO}_{2}-\mathrm{NC}$ (a, uncalcined), $\mathrm{SiO}_{2}-\mathrm{C}(\mathrm{b}$, calcined), $\mathrm{Ti}_{-}-\mathrm{SiO}_{2}$ (c), $\mathrm{W}-\mathrm{SiO}_{2}$ (d), and $\mathrm{NiMo} / \mathrm{W}-\mathrm{SiO}_{2}$ (e). Respective pore size distributions of different samples (f: $\mathrm{SiO}_{2}-\mathrm{NC}, \mathrm{g}: \mathrm{SiO}_{2}-\mathrm{C}$, h: $\mathrm{Ti}-\mathrm{SiO}_{2}$, i: $\mathrm{W}-\mathrm{SiO}_{2}$, and j: $\mathrm{NiMo} / \mathrm{W}-\mathrm{SiO}_{2}$ ).

$\mathrm{N}_{2}$-adsorption-desorption isotherms and pore size distribution of synthesized samples are presented in Fig. 1, and physical properties are shown in Table 1. As shown in Fig. 1, samples all exhibit type IV adsorption isotherm with H3 loop after calcination, indicating their mesoporous structure. The isotherms of Ti-/W-SiO 2 and $\mathrm{NiMo} / \mathrm{W}-\mathrm{SiO}_{2}$ are similar with that of $\mathrm{SiO}_{2}-\mathrm{C}$ with pronounced adsorption between 0.1 and 0.4 , which is due to pore filling caused by capillary condensation [16]. This exhibits the presence of hexagonal cylindrical channels of synthesized support $\mathrm{SiO}_{2}$ [17]. Meanwhile, for all samples (expect for $\mathrm{SiO}_{2}-\mathrm{NC}$ ) hysteresis loop is recorded, which is related to capillary 
condensation in mesopores. However, the adsorption in the same range $(0.1-0.4)$ for $\mathrm{SiO}_{2}-\mathrm{NC}$ is slow without obvious hysteresis loop, which is due to pore blocking cause by the presence of surfactant (CTMAB), therefore, causing the uneven distribution of pore size (Fig. 1f). Calcination at $550{ }^{\circ} \mathrm{C}$ is an effective method to remove CTMAB, leading to an increasing $\mathrm{N}_{2}$ adsorption, an enlarged surface area (Table 1), and a uniform distribution of pore size $(\sim 30 \AA)$ (Figs. 1g). Furthermore, variations in pore volume and pore size displayed in Table 1 also indicate the change in textural properties after calcination. With the incorporation of Ti/W species, the surface area decreases from 654.2 to $\sim 400 \mathrm{~m}^{2} \mathrm{~g}^{-1}$, indicating the pore blocking, thus leading to a decrease in pore volume (from 0.5 to $0.3 \mathrm{~cm}^{3} \mathrm{~g}^{-1}$ ) and a decline in $\mathrm{N}_{2}$ adsorption (Figs. 1h, i). Moreover, with the addition of NiMo species, a further decrease in pore volume and surface area can be observed, which indicates the formation of metal particles blocking internal pores. However, Fig. 1e) shows that $\mathrm{N}_{2}$ adsorption of $\mathrm{NiMo} / \mathrm{W}-\mathrm{SiO}_{2}$ increases significantly as compared to that of $\mathrm{W}-\mathrm{SiO}_{2}$, which is due to the formation of different porous structures derived from metal particles dispersed on the support surface [18].

The SEM images show that before calcination, the support particles are dispersed uniformly covered by a white shell-like material (CTMAB), leading to pore blocking and slow $\mathrm{N}_{2}$ adsorption (Fig. 2a). After calcination, the real morphology with sintering is presented in Fig. 2b, and many small particles ( $\mathrm{SiO}_{2}$ particles) can be found on its rough surface. With the addition of Ti/W species (Figs. 2c, d), the rough surface with small particles can be also detected, and no obvious metal particles are observed, demonstrating the uniform dispersion of metal particles without agglomeration, 
corresponding to the result of XRD. However, as NiMo species were incorporated in the system, many particles with larger size can be found obviously in Fig. 2e to make the surface rougher, indicating the formation of Ni/Mo metal nanoparticles.

Table 1 Physical properties and acid strength of synthesized catalysts.

Fig. $2 \mathrm{SEM}$ images of $\mathrm{SiO}_{2}-\mathrm{NC}(\mathrm{a}), \mathrm{SiO}_{2}-\mathrm{C}$ (b), $\mathrm{Ti}_{-} \mathrm{SiO}_{2}$ (c), $\mathrm{W}-\mathrm{SiO}_{2}$ (d), and $\mathrm{NiMo} / \mathrm{W}-\mathrm{SiO}_{2}(\mathrm{e})$.

The coordination environment of the incorporated Ti and $\mathrm{W}$ species was detected by UV-visible spectroscopy and spectra are presented in Fig. 3. No intense adsorption is observed for $\mathrm{SiO}_{2}$ absorption spectra, indicating no obvious ligand to metal charge transfer (LMCT) within hexagonal structure of $\mathrm{SiO}_{2}$. However, in case of $\mathrm{Ti}_{-} \mathrm{SiO}_{2}$, a strong absorption can be found at around $251 \mathrm{~nm}$, revealing a charge transfer from $2 \mathrm{p}$ orbital in tetrahedrally linked oxygen to $3 \mathrm{~d}$ orbital in Ti species, which is a characteristic peak of tetrahedral coordination environment of $\mathrm{Ti}^{4+}$ [19]. As for $\mathrm{W}^{-\mathrm{SiO}_{2}}$, no obvious peaks of $\mathrm{W}^{4+}$ and $\mathrm{W}^{5+}$ are observed between $400-700 \mathrm{~nm}$, in other words, $\mathrm{W}$ species of $\mathrm{W}-\mathrm{SiO}_{2}$ mainly exists in the form of 6 -valent oxide $\left(\mathrm{WO}_{3}\right)[20,21]$. Therefore, an intense absorption at around $261 \mathrm{~nm}$ is due to LMCT between $\mathrm{O}^{2-}$ ligands and $\mathrm{W}^{6+}$ cations of $\mathrm{WO}_{3}$ species linked to $\mathrm{SiO}_{2}$ surface.

Fig. 3 UV-visible diffuse reflectance spectra (DRS) of supports.

Meanwhile, FTIR spectra of supports are presented in Fig. 4. Obviously, all samples show a broad peak at $1089 \mathrm{~cm}^{-1}$, a sharp peak at $461 \mathrm{~cm}^{-1}$, and a weak one at $806 \mathrm{~cm}^{-1}$, which are assigned to the internal asymmetric stretching, bending vibration, and symmetric stretching of Si-O-Si linkage, respectively [22-24]. In addition, the peak 
located at $1632 \mathrm{~cm}^{-1}$ is attributed to $\mathrm{Si}-\mathrm{OH}$ group [25]. The curve of Ti/W- $-\mathrm{SiO}_{2}$ shows the presence of Ti/W-O-Si at around $960 \mathrm{~cm}^{-1}$, indicating that titanium/tungsten species exists in tetrahedral structure via coordination, corresponding to the result of UV-DRS. Additionally, incorporating metal oxides into $\mathrm{SiO}_{2}$ support leads to the creation of acidity (both $L$ and $B$ acid). The $B$ acid was partially attributed to the coordination of Si-OH group to $L$ center. Therefore, the presence of Si-OH group is important for obtaining abundant acidic sites.

Fig. 4 FTIR spectra of synthesized supports.

For measuring the acidity of synthesized samples, $\mathrm{NH}_{3}$-TPD was carried out. The results shown in Fig. 5 present that, $\mathrm{SiO}_{2}-\mathrm{C}$ presents a sharp peak at $160{ }^{\circ} \mathrm{C}$ and a weak one at around $300{ }^{\circ} \mathrm{C}$, which are assigned to weak acid sites, mainly originating from silicon center [26]. Grafting different metal oxides $\left(\mathrm{TiO}_{2}\right.$ and $\left.\mathrm{WO}_{3}\right)$ on support surface results in an increase in total amount of acidity (Table 1, increasing from $0.17 \mathrm{mmol} \mathrm{g}^{-}$ ${ }^{1}$ for $\mathrm{SiO}_{2}-\mathrm{C}$ to $\sim 0.4 \mathrm{mmol} \mathrm{g}^{-1}$ for $\mathrm{Ti} / \mathrm{W}-\mathrm{SiO}_{2}$ ) [27]. W-SiO 2 exhibits a higher peak at around $160{ }^{\circ} \mathrm{C}$ as compared to $\mathrm{SiO}_{2}-\mathrm{C}$, indicating weak acidic sites derived from hydroxyl group linked to silanol group which is associated with tungsten center via oxygen bridge (W-O-Si) [28]. On the other hand, similar peaks can be also observed for $\mathrm{Ti}-\mathrm{SiO}_{2}$, which is lower than those of $\mathrm{W}-\mathrm{SiO}_{2}$. It is suggested that with the incorporation of metal cations into silica, acidity (including $L$ and $B$ acidity) in these formed mixed oxides will be induced, which depends on the coordination of incorporated heteroatom and its amount of addition (Table 1, $6.82 \mathrm{wt} \%$ for W, $2.28 \mathrm{wt} \%$ for Ti) [29]. However, as $\mathrm{Ti}^{4+}$ species has the same state as $\mathrm{Si}^{4+}$, thus leading to a weaker 
effect for $\mathrm{Ti}_{-} \mathrm{SiO}_{2}$. Therefore, more acidity in $\mathrm{W}-\mathrm{SiO}_{2}\left(0.485 \mathrm{mmol} \mathrm{g}{ }^{-1}\right)$ has been detected than that in $\mathrm{Ti}^{-} \mathrm{SiO}_{2}\left(0.339 \mathrm{mmol} \mathrm{g}^{-1}\right)$. Catalyst support with higher acidity is more beneficial for supported metal dispersion, lignin-derived oxygen-containing groups adsorption, and $\mathrm{C}-\mathrm{O}$ linkages breaking [30, 31], which make $\mathrm{W}-\mathrm{SiO}_{2}$ potential for utilization as a support of NiMo catalysts during HDO process.

Fig. $5 \mathrm{NH}_{3}-\mathrm{TPD}$ of $\mathrm{SiO}_{2}-\mathrm{C}$ (blue line), $\mathrm{Ti}-\mathrm{SiO}_{2}$ (red line), and $\mathrm{W}-\mathrm{SiO}_{2}$ (black line). SA-XRD patterns of supports are shown in Fig. 6a. Except for $\mathrm{SiO}_{2}-\mathrm{NC}$, all samples exhibit a sharp diffraction peak at (100) reflection plane of $\mathrm{SiO}_{2}$, indicating its ordered hexagonal mesoporous structure [19]. Moreover, this characteristic diffraction peak shifts from $2.1^{\circ}$ for $\mathrm{SiO}_{2}-\mathrm{NC}$ to $2.8^{\circ}$ for $\mathrm{SiO}_{2}-\mathrm{C}$, indicating the structural change occurring after calcination. With the incorporation of Ti/W, no obvious shift appears in the diffraction peak at $2.8^{\circ}$, confirming that the synthesized catalysts also show the textural properties of $\mathrm{SiO}_{2}$. Above observations are corresponding to the results obtained from BET and SEM. Additionally, two broad diffraction peaks are observed at 4 and $4.8^{\circ}$ for $\mathrm{SiO}_{2}-\mathrm{C}$, which are assigned as a long-range array of hexagonal cylindrical porous structure [19]. However, these two peaks are absent after metal incorporation, suggesting a deterioration of the hexagonal structure as a result of isomorphic substitution [32].

WA-XRD patterns of support and NiMo supported catalysts are shown in Fig. $6 \mathbf{b}$. A broad peak at the range of $15-40^{\circ}(2 \theta)$ is assigned to amorphous silica, while no significant crystalline phase of $\mathrm{WO}_{x}$ is detected by WA-XRD, indicating the uniform dispersion of $\mathrm{W}$ species. On the other hand, for $\mathrm{NiMo} / \mathrm{SiO}_{2}$ diffraction peaks at $2 \theta=$ 
23.4, 25.7, and $27.3^{\circ}$ are observed and correspond to (110), (040), and (021) planes of $\mathrm{MoO}_{3}$ (orthorhombic crystalline phase) [33]. As compared to $\mathrm{NiMo} / \mathrm{SiO}_{2}$, no obvious peaks for Mo species and lower diffraction peaks at $37.3,43.4$, and $62.9^{\circ}$ originate from the reflection planes of (111), (200), and (220) of cubic phase of $\mathrm{NiO}$ can be observed in $\mathrm{NiMo} / \mathrm{W}-\mathrm{SiO}_{2}$ [34]. Above results indicate that the introduction of $\mathrm{W}$ species is beneficial for metal dispersion, especially for Mo species, which is corresponding to the result obtained in $\mathrm{NH}_{3}$-TPD.

For $\mathrm{NiMo} / \mathrm{W}-\mathrm{SiO}_{2}$, in order to get more information on doped species ( $\mathrm{Ni}$ and $\mathrm{Mo}$ ), especially for the non-detected one (Mo) by XRD analysis, Raman spectra have been performed. As shown in Fig. 6c, a pronounced peak located at $952 \mathrm{~cm}^{-1}$ coupled with a weak one at $706 \mathrm{~cm}^{-1}$ is detected which is due to the presence Ni species, while bands appearing at 821 and $896 \mathrm{~cm}^{-1}$ indicate the generation of crystalline $\mathrm{MoO}_{3}$ nanoparticles and the exist of $\mathrm{MoO}_{4}{ }^{2-}$, respectively [35]. The presence of $\mathrm{MoO}_{4}{ }^{2-}$ derived from the depolymerization of $\mathrm{Mo}_{7} \mathrm{O}_{24}{ }^{6-}$ illustrates the improved dispersion of Mo species in $\mathrm{NiMo} / \mathrm{W}-\mathrm{SiO}_{2}$, leading to no obvious diffraction peaks appearing in XRD pattern [36$38]$.

The results of $\mathrm{H}_{2}-\mathrm{TPR}$ of $\mathrm{NiMo} / \mathrm{W}-\mathrm{SiO}_{2}$ are shown in Fig. 6d. As depicted in Fig. 6d, a sharp peak at around $300-500{ }^{\circ} \mathrm{C}$ is recorded, which is the characteristic adsorption of the reduction of $\mathrm{Mo}^{6+}$ to $\mathrm{Mo}^{4+}$ species, while one small peak at around $600-700{ }^{\circ} \mathrm{C}$ is assigned to the characteristic peak of $\mathrm{NiO}$ species reduction, which is bound to support surface weakly $[39,40]$.

Fig. 6 (a) SA-XRD patterns of support and catalysts, (b) WA-XRD patterns of support 
and NiMo supported catalysts, (c) Raman spectrum of $\mathrm{NiMo} / \mathrm{W}-\mathrm{SiO}_{2}$, and (d) $\mathrm{H}_{2}-\mathrm{TPR}$ profile of $\mathrm{NiMo} / \mathrm{W}-\mathrm{SiO}_{2}$.

\section{Lignin depolymerization}

In this section, the effects of NiMo species and $\mathrm{W}$ promoter on lignin depolymerization were evaluated via lignin conversion, yields of bio-oil, char, and residual lignin (wt\%). As shown in Fig. 7, the highest yield of bio-oil (57.2 wt\%) is obtained over NiMo/W$\mathrm{SiO}_{2}$ catalyst, while that over $\mathrm{SiO}_{2}$ is only $18.2 \mathrm{wt} \%$, indicating the worse performance of $\mathrm{SiO}_{2}$ on lignin catalytic conversion. However, as compared to non-catalyst system, the introduction of $\mathrm{SiO}_{2}$ also makes positive effect on lignin conversion and bio-oil production. For $\mathrm{NiMo} / \mathrm{SiO}_{2}$, with the incorporation of NiMo species, the hydrotreatment ability is improved, resulting in the increase of bio-oil yield (from 18.2 $\mathrm{wt} \%$ for $\mathrm{SiO}_{2}$ to $46.3 \mathrm{wt} \%$ for $\mathrm{NiMo} / \mathrm{SiO}_{2}$ ) and a decrease in lignin residue (from 75.4 $\mathrm{wt} \%$ for $\mathrm{SiO}_{2}$ to $45.8 \mathrm{wt} \%$ for $\mathrm{NiMo} / \mathrm{SiO}_{2}$ ). It is suggested that the presence of active metal sites is beneficial for leading $\mathrm{H} \bullet$ (derived from the decomposition of formic acid and alcoholic solvent) to attack oxygen-containing groups and $\mathrm{C}-\mathrm{O}$ linkages, thus resulting in effective lignin depolymerization. Furthermore, the higher acidity produced by $\mathrm{W}$ promoter (as discussed via $\mathrm{NH}_{3}-\mathrm{TPD}$ ) favors adsorption and activation of chemical bonds (including $\mathrm{C}-\mathrm{C}$ and $\mathrm{C}-\mathrm{O}$ bonds in lignin), resulting in the linkage cleavage caused by heating program [41-43]. Therefore, abundant acidity coupled with active metal sites make $\mathrm{NiMo} / \mathrm{W}-\mathrm{SiO}_{2}$ more effective for lignin depolymerization. On the other hand, with the increase of acid strength, re-polymerization of lignin fragments to form char occurs easier, resulting in the slight increase of char yield ( $\leq 10 \mathrm{wt} \%)$. 
Fig. 7 Catalytic evaluation of lignin depolymerization over different synthesized catalysts.

\section{Recyclability test of catalyst}

For testing the recyclability of catalyst, lignin depolymerizaiton was performed at the same condition over $\mathrm{NiMo} / \mathrm{W}-\mathrm{SiO}_{2}$ for five times and each experiment was conducted for three times, and catalytic evaluation is presented in Table 2. With the increase of catalyst recyclability, surface area decreases dramatically with a decrease in pore volume, that is due to the blocking of porous structure caused by the coke deposition. Therefore, previously textural properties reappear with $321.2 \mathrm{~m}^{2} \mathrm{~g}^{-1}$ of surface area and $0.26 \mathrm{~cm}^{3} \mathrm{~g}^{-1}$ of pore volume after calcination. Although the catalyst $\mathrm{NiMo} / \mathrm{W}-\mathrm{SiO}_{2}$ contains excellent metal anchoring capacity, deteriorated performance on lignin conversion indicates a worse catalytic ability of catalyst, which is due to the coverage of active metal and acidic sites after reaction. After calcination for catalyst reactivation, large proportion of oxygen-containing guaiacols (G5-7) are identified over $\mathrm{SiO}_{2}(6.7$ $\mathrm{wt} \%$ ), leading to a low yield (1.0 wt \%) of alkyl guaiacols (G1-4), indicating that less 
hydrodeoxygenation pathway appears. With the addition of active metals (NiMo species), the hydrodeoxygenation ability of catalyst is improved, reflected in the increase of alkyl guaiacols yield $(8.9 \mathrm{wt} \%)$. There are two main reasons for its improvement: (I) $\mathrm{Mo}^{4+}$ species in reduced Mo oxides formed at low reduction temperature performs as electron deficient active sites, absorbing oxygen-containing guaiacol molecule on catalyst surface via coordinating with oxygen atom of C-O bonds, thus resulting in the activation of $\mathrm{C}-\mathrm{O}$ bonds $[44,45]$. (II) Ni species promotes the activation of molecular $\mathrm{H}_{2}$ produced from the decomposition of formic acid and solvent [4]. Therefore, the cooperation between $\mathrm{Ni}$ and $\mathrm{Mo}^{4+}$ species enhances HDO performance of lignin depolymerization, thus leading to an increasing trend of alkyl guaiacols. Furthermore, the higher acidity provided by $\mathrm{W}$ promoter can further enhance the adsorption and activation of chemical bonds, leading to the further conversion of 2methoxy-4-methylphenol to guaiacol via demethylation.

The depolymerization of lignin over $\mathrm{NiMo} / \mathrm{W}-\mathrm{SiO}_{2}$ occurs through four main steps (Fig. 9): (I) direct depolymerization of lignin over $\mathrm{SiO}_{2}$ with assistance of formic acid acting as internal hydrogen donor, (II) hydrodeoxygenation of oxygen-containing guaiacols over NiMo active species (the promotion of $\mathrm{H}_{2}$ activation from Ni species and the adsorption of C-O bonds from reduced Mo oxides), (III) adsorption, activation, and cleavage of C-O bonds over acidic sites (from support and W species), and (IV) further demethylation of 2-methoxy-4-methylphenol via the cooperation of NiMo species and acidic sites.

Fig. 8 The main monomers (wt\%) produced from lignin depolymerization over 
NiMo/W-SiO 2 (G1: guaiacol, G2: 2-methoxy-4-methylphenol, G3: 4-ethylguaiacol,

G4: 2-methoxy-4-(1-propyl)phenol, S1: 2,6-dimethoxyphenol, G5: vanillin, G6: 4hydroxy-3-methoxyacetophenone, G7: 4-hydroxy-3-methoxypropiophenone). catalysts with assistance of formic acid used as an internal hydrogen donor.

\section{Conclusions}

Fig. 9 Possible reaction mechanism of lignin depolymerization over supported metal

The in situ HDO process of EHL with internal hydrogen source provided from the decomposition of formic acid was investigated over $\mathrm{NiMo} / \mathrm{W}-\mathrm{SiO}_{2}$ catalyst. Due to the heating effect, the in situ hydrogen provided from formic acid was driven by active metal sites to participate in lignin conversion, where Ni favored the introduction of hydrogen in hydrotreatment, and Mo species preferred adsorbing C-O-C bonds on catalyst surface. In the absence of active metal sites, the degradation of lignin was mainly derived from the functionality of acidic sites which favored the absorption and activation of chemical bonds in lignin, leading to an initial decomposition of lignin.

\section{Method}

\section{Materials}

Lignin used was enzymatic hydrolysis lignin (EHL, with Mw and Mn of 3259 and 1385 g $\mathrm{mol}^{-1}$, respectively), which was friendly provided from Shandong Longli Biotechnology Co., Ltd. (Shandong, China). Before experiments, EHL was purified via an alkali pretreatment to obtain the extracted lignin, because the presence of cellulose and hemicellulose would cause a negative effect on lignin depolymerization and the processing steps were presented in our previous research [46]. After that, the extracted 
lignin was dried at $105{ }^{\circ} \mathrm{C}$ for $12 \mathrm{~h}$, and lignin used in the following experiment was assigned to extracted lignin. The proximate, ultimate, and component analyses of raw and extracted lignin are presented in Table 3.

Table 3. Proximate, ultimate, and component analyses of raw and extracted lignin.

\section{Synthesis of support}

Support $\mathrm{SiO}_{2}$ was prepared according to a previous research with a molar ratio of 2:1:0.2:0.25 of $\mathrm{NaOH}$ (95 \%): $\mathrm{SiO}_{2}$ (99..99 \%):TMAOH (tetramethylammonium hydroxide, $25 \%$ aqueous solution):CTMAB (cetyltrimethylammonium bromide, $99 \%$ ), respectively [48]. Typically, $\mathrm{NaOH} / \mathrm{SiO}_{2}$ solution (solution I) was obtained by the preparation of $\mathrm{NaOH}$ solution in $80 \mathrm{~mL}$ deionized water followed by the addition of $\mathrm{SiO}_{2}$. The mixed solution was stirred at $70{ }^{\circ} \mathrm{C}\left( \pm 2{ }^{\circ} \mathrm{C}\right)$ for $30 \mathrm{~min}$ to gain a transparent phase. Afterwards, continuous stir was maintained until the solution was cooled down to room temperature. Meanwhile, a surfactant solution (solution II) was produced with determined amount of TMAOH in $150 \mathrm{~mL}$ deionized water followed by the addition of CTMAB. After 30 min stir, solution I was dropwise added to solution II, and $\mathrm{pH}$ was adjusted to 8-10 using diluted $\mathrm{H}_{2} \mathrm{SO}_{4}\left(0.25 \mathrm{~mol} \mathrm{~L}^{-1}\right)$, and then the obtained suspension was kept at $70{ }^{\circ} \mathrm{C}\left( \pm 2{ }^{\circ} \mathrm{C}\right)$ for $2 \mathrm{~h}$ with magnetic agitation. Finally, the mixture was aged at room temperature for $24 \mathrm{~h}$, and the gel generated later was separated by filtration and centrifuged for several times with deionized water until neutral, which was named as $\mathrm{SiO}_{2}-\mathrm{NC}$ (uncalcined). After being calcined at $550{ }^{\circ} \mathrm{C}$ for $8 \mathrm{~h}$ with a heating rate of

$1{ }^{\circ} \mathrm{C} \mathrm{min}^{-1}$, the prepared sample was assigned to $\mathrm{SiO}_{2}-\mathrm{C}$ (calcined). Except for TMAOH (Aladdin, Shanghai, China), other chemical regents were all purchased from Macklin 
(Shanghai, China).

\section{Preparation of $\mathrm{Ti} / \mathrm{W}$ incorporated $\mathrm{SiO}_{2}$}

The modification of synthesized support was carried out by wetness impregnation method [49], using titanium(IV) isopropoxide (Ti(OiPr) $4,99.9 \%$ ) and ammonium metatungstate hydrate $\left(\left(\mathrm{NH}_{4}\right)_{6} \mathrm{H}_{2} \mathrm{~W}_{12} \mathrm{O}_{40} \cdot x \mathrm{H}_{2} \mathrm{O}, 99.5 \%\right)$ as metal precursors. In a typical process, $\mathrm{SiO}_{2}-\mathrm{C}(5 \mathrm{~g})$ was dispersed in $40 \mathrm{~mL}$ anhydrous ethanol ( $\left.\geq 99.5 \%\right)$, which initially dissolved determined amount of metal precursors to obtain nominal metal loading of $0.5 \mathrm{mmol} \mathrm{Ti} / \mathrm{W}$ per $\mathrm{SiO}_{2}$. The obtained suspension was maintained at room temperature with magnetic stir for $8 \mathrm{~h}$. After that, the sample was filtered and washed with anhydrous ethanol for three times and dried at $75^{\circ} \mathrm{C}$ overnight. Calcination process was performed at $500{ }^{\circ} \mathrm{C}$ for $4 \mathrm{~h}$ with a heating rate of $1{ }^{\circ} \mathrm{C} \mathrm{min}^{-1}$, and the obtained sample was named as $\mathrm{Ti}-/ \mathrm{W}-\mathrm{SiO}_{2}$. All chemicals used were all purchased from Macklin (Shanghai, China).

\section{Preparation of NiMo supported catalyst}

NiMo supported catalysts on $\mathrm{SiO}_{2}$ and $\mathrm{W} / \mathrm{SiO}_{2}$, respectively, were prepared with total metal loading of $10 \mathrm{mmol} \mathrm{Ni}+\mathrm{Mo}(\mathrm{Ni} / \mathrm{Mo}=1: 1$, molar ratio $)$ per support via coimpregnation method. In a typical synthesis, nickel(II) nitrate hexahydrate (99.9\%) and ammonium molybdate tetrahydrate $(99.9 \%)$ were employed as Ni and Mo precursors, respectively. After impregnation, the catalyst was dried as $105^{\circ} \mathrm{C}$ for $6 \mathrm{~h}$ and calcined at $500{ }^{\circ} \mathrm{C}$ for $4 \mathrm{~h}$ with a heating rate of $1{ }^{\circ} \mathrm{C} \mathrm{min}^{-1}$. Before their utilization, NiMo supported catalysts were all reduced at $400{ }^{\circ} \mathrm{C}$ under $\mathrm{H}_{2}\left(5 \% \mathrm{H}_{2}\right.$ in $\left.\mathrm{N}_{2}\right)$. All chemicals used were purchased from Macklin (Shanghai, China). 
The physical properties (i.e., Brunauer-Emmett Teller (BET) surface area, pore volume,

355 and pore size) and adsorption-desorption isotherms of synthesized samples were measured by a Tristar II series, micrometric analyzer at $\mathrm{N}_{2}$ atmosphere $\left(77 \mathrm{~K},-196^{\circ} \mathrm{C}\right)$. Surface area was determined using BET method and the distribution of pore size was calculated by BJH (Barret-Joyner-Halenda) method. The surface morphology of samples was recorded by scanning electron microscopy (SEM). UV-visible spectra of supports were performed in the range of 200-800 $\mathrm{nm}$ on a UV-2401PC Shimadzu spectrophotometer coupled with an integrating diffuse reflectance sphere (ISR 240A) and using $\mathrm{BaSO}_{4}$ as reference material. The FTIR (Fourier Transform Infrared) was conducted on FTIR spectrometer (VERTEX 70 series, Bruker) with sample powder dispersed in $\mathrm{KBr}$. $\mathrm{NH}_{3}$-TPD (temperature programmed desorption) and $\mathrm{H}_{2}-\mathrm{TPR}$ (temperature programmed reduction) were all performed on a Micromeritics AutoChem II 2920 automatic analyzer coupled with a thermal conductivity detector. Before $\mathrm{NH}_{3}$ adsorption, the sample was treated in situ at $500{ }^{\circ} \mathrm{C}$ for 30 min under He stream to eliminate water and other contaminants. Afterwards, the sample was cooled down to $120{ }^{\circ} \mathrm{C}$ and contacted with $\mathrm{He} / \mathrm{NH}_{3}$ mixed gas $(90 / 10$, molar ratio) for 30 min with the

370 flow rate of $20 \mathrm{~mL} \mathrm{~min}^{-1}$. $\mathrm{NH}_{3}$ desorption process was conducted in He stream with the 371 flow rate of $20 \mathrm{~mL} \mathrm{~min}-1$ at a heating rate of $10{ }^{\circ} \mathrm{C} \min ^{-1}$ until reaching the temperature 372 of $500{ }^{\circ} \mathrm{C}$. Before $\mathrm{H}_{2}$ reduction experiment, the sample was pretreated in situ at $500{ }^{\circ} \mathrm{C}$ 373 for $2 \mathrm{~h}$ under air flow and cooled down to room temperature at Ar flow. The reduction process was conducted under $\mathrm{Ar} / \mathrm{H}_{2}$ mixture (90/10, molar ratio) with flow rate of 20 
$\mathrm{mL} \min ^{-1}$ at a heating rate of $10{ }^{\circ} \mathrm{C} \min ^{-1}$ from room temperature to $800{ }^{\circ} \mathrm{C}$. X-ray diffractions (XRD) of synthesized supports were conducted via small angle (SA) X-ray scattering diffractometer with $\mathrm{Cu} \mathrm{K \alpha}(\lambda=0.1542 \mathrm{~nm})$ (Bruker) in the degree range of $0.6-8{ }^{\circ}$ with a step rate of $0.02{ }^{\circ} \mathrm{s}^{-1}$. The wide angle (WA) XRD patterns of catalysts were obtained on an X-ray diffractometer (Bruker D8 advance) equipped with $\mathrm{Cu} \mathrm{K} \alpha$ $\left(\lambda=0.1542 \mathrm{~nm}\right.$ ) radiation run at $40 \mathrm{kV}$ and $40 \mathrm{~mA}$ between 2 and $80^{\circ}$ with the same step rate of SA-XRD. Raman spectra of samples were recorded on a Renishaw in Via Raman Microscope spectrometer coupled with a laser source at $514 \mathrm{~nm}$, at $200 \mathrm{~mW}$ power.

\section{Lignin depolymerization}

Lignin depolymerization experiment was performed in a stainless steel reactor with magnetic stir $(100 \mathrm{~mL})$. In a typical experiment, lignin $(0.5 \mathrm{~g})$ and catalyst $(0.5 \mathrm{~g})$ were added into isopropanol (50 mL, $\geq 99.9 \%$ ) with magnetic stir and dispersed by further ultrasonic treatment for $10 \mathrm{~min}$. After that, $5 \mathrm{~mL}$ formic acid was mixed with the previous suspension with stir, and then the reactor was purged with He several times (but not being pressurized) to check for leaks and remove internal air, and heated from room temperature to $240{ }^{\circ} \mathrm{C}$ with a heating rate of $10{ }^{\circ} \mathrm{C} \mathrm{min}-1$ for $8 \mathrm{~h}$. At the end of reaction, the reactor was quenched with ice water and cooled down to room temperature. Each experiment was repeated for three times ensure the reproducibility.

The obtained products were in components of gas, liquid, and solid (including residual lignin, char, and catalyst). As the content of gaseous products was less than 1 $\mathrm{wt} \%$ (based on initial weight of lignin), thus they were ignored in the following analysis. In a typical separation step (Fig. 10), gaseous products were released into the air after 
opening the reactor. Liquid and solid phases were separated by washing the reactor with $30 \mathrm{~mL}$ dichloromethane (DCM, $99.5 \%$ ) for three times followed by filtration. Subsequently, lignin derived bio-oil was formed by evaporation at $55{ }^{\circ} \mathrm{C}$ and $160 \mathrm{mbar}$ using a rotary evaporator to remove DCM, isopropanol, and water (generated during lignin depolymerization). Residual lignin was gained by washing solid phase with $\mathrm{NaOH}$ solution $\left(20 \mathrm{~mL}, 0.25 \mathrm{~mol} \mathrm{~L}^{-1}\right)$ for three times, and collected via acid precipitation with a $\mathrm{HCl}$ solution $\left(0.10 \mathrm{~mol} \mathrm{~L}^{-1}\right)$ followed by filtration. After being washed with deionized water and centrifuged for three times, the obtained unreacted lignin was dried at $105^{\circ} \mathrm{C}$ for $12 \mathrm{~h}$. The spent catalyst (including catalyst and char) was obtained after separating residual lignin from solid phase, and used for catalyst recyclability test. Finally, the reactivation of spent catalyst was carried out by calcination at $500{ }^{\circ} \mathrm{C}$ with a heating rate of $1{ }^{\circ} \mathrm{C} \mathrm{min}^{-1}$ for $2 \mathrm{~h}$ followed by $\mathrm{H}_{2}$ flow reduction.

Fig. 10 Separation steps of depolymerized phases.

\section{Depolymerized products analysis and measurement}

The product analysis was performed by the application of gas chromatography-mass spectrometer (GC-MS, Agilent 7890 GC with an Agilent 5975 inert MS indicator, Agilent Technologies Inc., USA), coupled with a HP-INNOWAX capillary column (30 $\mathrm{m} \times 0.25 \mathrm{~mm} \times 0.25 \mu \mathrm{m})$. The injection of sample was $1 \mu \mathrm{L}$, and the identification of depolymerized products was based on NIST library. In a typical temperature program, internal oven temperature was started from $60^{\circ} \mathrm{C}$, maintained for $2 \mathrm{~min}$, to $250{ }^{\circ} \mathrm{C}$ with a heating rate of $10^{\circ} \mathrm{C} \mathrm{min}^{-1}$, and kept for $10 \mathrm{~min}$. The quantitative measurement of 
mainly recorded products was measured by external standard method using analytical

420

standard chemicals (e.g., guaiacol, 2-methoxy-4-methylphenol, 4-ethylguaiacol, 2Methoxy-4-(1-propyl)phenol, 2,6-Dimethoxyphenol, vanillin, 4-hydroxy-3methoxyacetophenone, 4-hydroxy-3-methoxypropiophenone). All chemicals used as standards were purchased from Aladdin (Shanghai, China), and high-purity gas (He, $99.999 \%$ ) used in the experiment was purchased from Nanjing Special Gas Factory Co., Ltd. (Nanjing, China).

Lignin conversion, yields of bio-oil, unreacted lignin, and char were determined by Eqs. (1)-(4), respectively. Furthermore, yields of main phenolic monomers (guaiacol, 2-methoxy-4-methylphenol, 4-ethylguaiacol， 2-Methoxy-4-(1-propyl)phenol， 2,6Dimethoxyphenol, vanillin, 4-hydroxy-3-methoxyacetophenone, 4-hydroxy-3methoxypropiophenone) were obtained by Eq. (5).

Lignin conversion $(w t \%)=\left(\frac{w e i g h t \text { of initial lignin }- \text { weight of residual lignin }}{\text { weight of initial lignin }}\right) \times 100 \%$ (1) Bio-oil $(w t \%)=\left(\frac{\text { weight of bio-oil }}{\text { weight of initial lignin }}\right) \times 100 \%$ (2)

Unreacted lignin $(w t \%)=\left(\frac{\text { weight of residual lignin }}{\text { weight of initial lignin }}\right) \times 100 \%$

$\operatorname{Char}(w t \%)=\left(\frac{\text { weight of solid residue-weight of catalyst }}{\text { weight of initial lignin }}\right) \times 100 \%$ (4)

Phenolic monomer $(w t \%)=\left(\frac{\text { weight of a phenolic monomer }}{\text { weight of initial lignin }}\right) \times 100 \%$

Elemental analysis of lignin was conducted on $\mathrm{CNH}$ mode with a Vario EL III to determine the content of carbon, nitrogen and hydrogen, and that of oxygen was measured by difference.

\section{List of abbreviations}

EHL: enzymatic hydrolysis lignin; HDO: hydrodeoxygenation; $\mathrm{SiO}_{2}-\mathrm{NC}$ (uncalcined); 
$\mathrm{SiO}_{2}-\mathrm{C}$ (calcined); LMCT: ligand to metal charge transfer; DRS: Diffuse Reflectance

438 Spectra; TMAOH: tetramethylammonium hydroxide; CTMAB:

439 cetyltrimethylammonium bromide; BET: Brunauer-Emmett Teller; BJH: Barret-

440 Joyner-Halenda; SEM: Scanning Electron Microscopy; FTIR: Fourier Transform

441 Infrared; $\mathrm{NH}_{3}$-TPD: $\mathrm{NH}_{3}$ Temperature Programmed Desorption; $\mathrm{H}_{2}-\mathrm{TPR}: \mathrm{H}_{2}$

442 Temperature Programmed Reduction; XRD: X-Ray Diffractions; SA: Small Angle; WA:

443 Wide Angle; DCM: dichloromethane; GC-MS: Gas Chromatography-Mass

444 Spectrometer.

445 Declarations

446 Ethics approval and consent to participate

$447 \quad$ Not applicable

448 Consent for publication

449 Not applicable

$450 \quad$ Availability of data and materials

451 All data obtained in this study are included in this paper. Raw data are available on

452 reasonable request.

453 Competing interests

454 The authors declare that they have no competing interests.

$455 \quad$ Funding

456 National Natural Science Foundation of China (no.21774059) and the Priority 457 Academic Program Development (PAPD) of Jiangsu Higher Education Institutions. 
Conceptualization, X.L.; methodology, H.M.R.; software, H.G.; validation, D.W., P.X. and J.C.; formal analysis, C.X.; investigation, X.G.; resources, X.G.; data curation, X.L.; writing-original draft preparation, X.L.; writing-review and editing, X.G.; visualization, H.M.R.; supervision, X.G.; project administration, C.X.; funding acquisition, X.G. All authors have read and agreed to the published version of the manuscript.

\section{Acknowledgements}

This research was financially supported by the National Natural Science Foundation of China (no.21774059), the Priority Academic Program Development (PAPD) of Jiangsu Higher Education Institutions, the opening funding of Jiangsu Key Lab of Biomass based Green Fuels and Chemicals.

\section{References}

1. Azadi P, Inderwildi OR, Farnood R, King DA. Liquid fuels, hydrogen and chemicals from lignin: A critical review. Renew Sustain Energ Rev. 2013;21:50623. https://doi.org/10.1016/j.rser.2012.12.022.

2. Huber GW, Iborra S, Corma A. Synthesis of Transportation Fuels from Biomass: Chemistry, Catalysts, and Engineering. Chem Rev. 2006;106:4044-98. https://doi.org/10.1021/cr068360d.

3. Mortensen PM, Grunwaldt JD, Jensen PA, Knudsen KG, Jensen AD. A review of catalytic upgrading of bio-oil to engine fuels. Appl Catal A-Gen. 2011;407:1-19. https://doi.org/10.1016/j.apcata.2011.08.046.

4. Raikwar D, Munagala M, Majumdar S, Shee D. Hydrodeoxygenation of guaiacol over Mo, W and Ta modified supported nickel catalysts. Catal Today. 
5. Mood SH, Golfeshan AH, Tabatabaei M, Jouzani GS, Najafi G, Gholami M et al. Lignocellulosic biomass to bioethanol, a comprehensive review with a focus on $\begin{array}{llll}\text { pretreatment. } & \text { Renew } & \text { Sustain } & \text { Energ }\end{array}$ https://doi.org/10.1016/j.rser.2013.06.033.

6. Alonso DM, Wettstein SG, Mellmer MA, Gurbuz EI, Dumesic JA. Integrated conversion of hemicellulose and cellulose from lignocellulosic biomass. Energ Environ Sci. 2013;6:76-80. https://doi.org/10.1039/c2ee23617f.

7. Tomás-Pejó E, Fermoso J, Herrador E, Hernando H, Jiménez-Sánchez S, Ballesteros $\mathrm{M}$ et al. Valorization of steam-exploded wheat straw through a biorefinery approach: Bioethanol and bio-oil co-production. Fuel. 2017;199:40312. https://doi.org/10.1016/j. fuel.2017.03.006.

8. Kumar A, Kumar A, Biswas B, Kumar J, Yenumala SR, Bhaskar T. Hydrodeoxygenation of m-Cresol over Ru based catalysts: Influence of catalyst support on m-Cresol conversion and methylcyclohexane selectivity. Renew Energ. 2020;151:687-97. https://doi.org/10.1016/j.renene.2019.11.076.

9. Isa KM, Abdullah TAT, Ali UFM. Hydrogen donor solvents in liquefaction of biomass: A review. Renew Sustain Energ Rev. 2018;81:1259-68. https://doi.org/10.1016/j.rser.2017.04.006.

10. Guan W, Tsang CW, Lin CSK, Len C, Hu H, Liang C. A review on high catalytic efficiency of solid acid catalysts for lignin valorization. Bioresour Technol. 2020;298:122432. https://doi.org/10.1016/j.biortech.2019.122432. 
11. Li B, Liu Y, Li R, Yang T, Kai X. Aluminum-water reactions assisted in situ hydrodeoxygenation of enzymolysis lignin from bioconversion of rice straw over NiMo catalyst. Ind Crop Prod. 2020;154:112727. https://doi.org/10.1016/j.indcrop.2020.112727.

12. Priharto N, Ronsse F, Prins W, Hita I, Deuss PJ, Heeres HJ. Hydrotreatment of pyrolysis liquids derived from second-generation bioethanol production residues over NiMo and CoMo catalysts. Biomass Bioenerg. 2019;126:84-93. https://doi.org/10.1016/j.biombioe.2019.05.005.

13. Kordouli E, Pawelec B, Kordulis C, Lycourghiotis A, Fierro JLG. Hydrodeoxygenation of phenol on bifunctional Ni-based catalysts: Effects of Mo promotion and support. Appl Catal B-Environ. 2018;238:147-60. https://doi.org/10.1016/j.apcatb.2018.07.012.

14. Wang C, Li Z, Wu K, Liu J, Yang X, Kong X et al. Synthesis of Ni-Mo-N catalysts for removing oxygen from acetophenone. Biomass Bioenerg. 2020;133:105448. https://doi.org/10.1016/j.biombioe.2019.105448.

15. Sangnikul P, Phanpa C, Xiao R, Zhang H, Reubroycharoen P, Kuchonthara P et al. Role of copper- or cerium-promoters on $\mathrm{NiMo} / \gamma-\mathrm{Al}_{2} \mathrm{O}_{3}$ catalysts in hydrodeoxygenation of guaiacol and bio-oil. Appl Catal A-Gen. 2019;574:151-60. httpss://doi.org/10.1016/j.apcata.2019.02.004.

16. Appaturi JN, Adam F, Khanam Z. A comparative study of the regioselective ring opening of styrene oxide with aniline over several types of mesoporous silica materials. Micropor Mesopor Mat. 2012;156:16-21. 
https://doi.org/10.1016/j.micromeso.2012.01.023.

17. Ambursa MM, Sudarsanam P, Voon LH, Hamid SBA, Bhargava SK. Bimetallic $\mathrm{Cu}-\mathrm{Ni}$ catalysts supported on MCM-41 and Ti-MCM-41 porous materials for hydrodeoxygenation of lignin model compound into transportation fuels. Fuel Process Technol. 2017;162:87-97. https://doi.org/10.1016/j.fuproc.2017.03.008.

18. Totong S, Daorattanachai P, Laosiripojana N, Idem R. Catalytic depolymerization of alkaline lignin to value-added phenolic-based compounds over $\mathrm{Ni} / \mathrm{CeO}_{2}-\mathrm{ZrO}_{2}$ catalyst synthesized with a one-step chemical reduction of $\mathrm{Ni}$ species using $\mathrm{NaBH}_{4}$ as the reducing agent. Fuel Process Technol. 2020;198. https://doi.org/10.1016/j.fuproc.2019.106248.

19. Lin K, Pescarmona PP, Vandepitte H, Liang D, Van Tendeloo G, Jacobs PA. Synthesis and catalytic activity of Ti-MCM-41 nanoparticles with highly active titanium sites. J Catal. 2008;254:64-70. https://doi.org/10.1016/j.jcat.2007.11.017.

20. Wu JF, Ramanathan A, Biancardi A, Jystad AM, Caricato M, Hu Y et al. Correlation of Active Site Precursors and Olefin Metathesis Activity in WIncorporated Silicates. ACS Catal. 2018;8:10437-45. https://doi.org/10.1021/acscatal.8b03263.

21. Yang XL, Gao R, Dai WL, Fan K. Influence of tungsten precursors on the structure and catalytic properties of $\mathrm{WO}_{3} / \mathrm{SBA}-15$ in the selective oxidation of cyclopentene to glutaraldehyde. J Phys Chem C. 2008;112:3819-26. https://doi.org/10.1021/jp710409g.

22. Popova M, Szegedi Á, Németh P, Kostova N, Tsoncheva T. Titanium modified 
MCM-41 as a catalyst for toluene oxidation. Catal Commun. 2008;10:304-8. https://doi.org/10.1016/j.catcom.2008.09.008.

23. Anunziata OA, Beltramone AR, Cussa J. Synthesis at atmospheric pressure and characterization of highly ordered Al, V, and Ti-MCM-41 mesostructured catalysts. Catal Today. 2008;133-135:891-6. https://doi.org/10.1016/j.cattod.2007.12.086.

24. Wang S, Ma C, Shi Y, Ma X. Ti incorporation in MCM-41 mesoporous molecular sieves using hydrothermal synthesis. Front Chem Sci Eng. 2014;8:95-103. https://doi.org/10.1007/s11705-014-1405-2.

25. Rao KS, El-Hami K, Kodaki T, Matsushige K, Makino K. A novel method for synthesis of silica nanoparticles. J Colloid Interf Sci. 2005;289:125-31. https://doi.org/10.1016/j.jcis.2005.02.019.

26. Gianotti E, Dellarocca V, Marchese L, Martra G, Coluccia S, Maschmeyer T. NH3 adsorption on MCM-41 and Ti-grafted MCM-41. FTIR, DR UV-Vis-NIR and photoluminescence studies. Phys Chem Chem Phys. 2002;4:6109-15. https://doi.org/10.1039/b207231a.

27. Méndez FJ, Bravo-Ascención G, González-Mota M, Puente-Lee I, Bokhimi X, Klimova TE. NiMo catalysts supported on Al, Nb, Ti or Zr-containing MCM-41 for dibenzothiophene hydrodesulfurization. Catal Today. 2020;349:217-27. https://doi.org/10.1016/j.cattod.2018.03.039.

28. Chen X, Liu J, Yan H, Zhou X, Yao S, Wang Y et al. Insight into the Effect of Lewis Acid of W/Al-MCM-41 Catalyst on Metathesis of 1-Butene and Ethylene. Appl Catal A-Gen. 2020;604:117772. https://doi.org/10.1016/j.apcata.2020.117772. 
29. Carniti P, Gervasini A, Marzo M. Silica-niobia oxides as viable acid catalysts in water: Effective vs. intrinsic acidity. Catal Today. 2010;152:42-7. https://doi.org/10.1016/j.cattod.2009.07.111.

30. Zhang S, Su L, Liu L, Fang G. Degradation on hydrogenolysis of soda lignin using $\mathrm{CuO} / \mathrm{SO}_{4}{ }^{2-} / \mathrm{ZrO}_{2}$ as catalyst. Ind Crop Prod. 2015;77:451-7. https://doi.org/10.1016/j.indcrop.2015.07.039.

31. Lu M, Jiang Y, Sun Y, Zhang P, Zhu J, Li M et al. Hydrodeoxygenation of Guaiacol Catalyzed by $\mathrm{ZrO}_{2}-\mathrm{CeO}_{2}$-Supported Nickel Catalysts with High Loading. Energ Fuel. 2020;34:4685-92. https://doi.org/10.1021/acs.energyfuels.0c00445.

32. Mokaya R, Jones W. Physicochemical Characterisation and Catalytic Activity of Primary Amine Templated Aluminosilicate Mesoporous Catalysts. J Catal. 1997;172:211-21. https://doi.org/10.1006/jcat.1997.1851.

33. Mendez FJ, Bravo-Ascencion G, Gonzalez-Mota M, Puente-Lee I, Bokhimi X, Klimova TE. NiMo catalysts supported on Al, Nb, Ti or Zr-containing MCM-41 for dibenzothiophene hydrodesulfurization. Catal Today. 2020;349:217-27. httpss://doi.org/10.1016/j.cattod.2018.03.039.

34. Ambursa MM, Sudarsanam P, Voon LH, Abd Hamid SB, Bhargava SK. Bimetallic $\mathrm{Cu}-\mathrm{Ni}$ catalysts supported on MCM-41 and Ti-MCM-41 porous materials for hydrodeoxygenation of lignin model compound into transportation fuels. Fuel Process Technol. 2017;162:87-97. https://doi.org/10.1016/j.fuproc.2017.03.008.

35. Kordouli E, Pawelec B, Kordulis C, Lycourghiotis A, Fierro JLG. Hydrodeoxygenation of phenol on bifunctional Ni-based catalysts: Effects of Mo 
promotion and support. Appl Catal B-Environ. 2018;238:147-60. https://doi.org/10.1016/j.apcatb.2018.07.012.

593

36. Spanos N, Vordonis L, Kordulis C, Lycourghiotis A. Molybdenum-oxo species deposited on alumina by adsorption: I. Mechanism of the Adsorption. Journal of Catalysis. 1990;124:301-14. https://doi.org/10.1016/0021-9517(90)90179-N.

37. Dzwigaj S, Louis C, Breysse M, Cattenot M, Bellière V, Geantet C et al. New generation of titanium dioxide support for hydrodesulfurization. Appl Catal BEnviron. 2003;41:181-91. https://doi.org/10.1016/S0926-3373(02)00210-2.

38. Gao J, Zheng Y, Jehng JM, Tang Y, Wachs IE, Podkolzin SG. Identification of molybdenum oxide nanostructures on zeolites for natural gas conversion. Science. 2015;348:686. https://doi.org/10.1126/science.aaa7048.

39. Rynkowski JM, Paryjczak T, Lenik M. On the nature of oxidic nickel phases in $\mathrm{NiO} / \gamma-\mathrm{Al}_{2} \mathrm{O}_{3} \quad$ catalysts. Appl Catal A-Gen. 1993;106:73-82. https://doi.org/10.1016/0926-860X(93)80156-K.

40. Bakhtyari A, Sakhayi A, Rahimpour MR, Raeissi S. Upgrading of cyclohexanone to hydrocarbons by hydrodeoxygenation over nickel-molybdenum catalysts. Int $\mathrm{J}$ Hydrogen Energ. 2020;45:11062-76. https://doi.org/10.1016/j.ijhydene.2020.02.036.

41. Zhang X, Wang T, Ma L, Zhang Q, Yu Y, Liu Q. Characterization and catalytic properties of $\mathrm{Ni}$ and $\mathrm{NiCu}$ catalysts supported on $\mathrm{ZrO}_{2}-\mathrm{SiO}_{2}$ for guaiacol hydrodeoxygenation. https://doi.org/10.1016/j.catcom.2012.12.011. 
613

42. Fogassy G, Thegarid N, Schuurman Y, Mirodatos C. From biomass to bio-gasoline by FCC co-processing: effect of feed composition and catalyst structure on product quality. Energ Environ Sci. 2011;4:5068-76. https://doi.org/10.1039/c1ee02012a.

43. Zhang H, Cheng Y-T, Vispute TP, Xiao R, Huber GW. Catalytic conversion of biomass-derived feedstocks into olefins and aromatics with ZSM-5: the hydrogen to carbon effective ratio. Energ Environ Sci. 2011;4:2297-307. https://doi.org/10.1039/c1ee01230d.

44. Chen N, Gong S, Qian EW. Effect of reduction temperature of $\mathrm{NiMoO}_{3}-\mathrm{x} / \mathrm{SAPO}-$ 11 on its catalytic activity in hydrodeoxygenation of methyl laurate. Appl Catal BEnviron. 2015;174-175:253-63. https://doi.org/10.1016/j.apcatb.2015.03.011.

45. Olcese RN, Bettahar M, Petitjean D, Malaman B, Giovanella F, Dufour A. Gasphase hydrodeoxygenation of guaiacol over $\mathrm{Fe} / \mathrm{SiO}_{2}$ catalyst. Appl Catal BEnviron. 2012;115-116:63-73. https://doi.org/10.1016/j.apcatb.2011.12.005.

46. Lu X, Dai P, Zhu X, Guo H, Que H, Wang D et al. Thermal behavior and kinetics of enzymatic hydrolysis lignin modified products. Thermochim Acta. 2020;688. https://doi.org/10.1016/j.tca.2020.178593.

47. Alves A, Schwanninger M, Pereira H, Rodrigues J. Analytical pyrolysis as a direct method to determine the lignin content in wood - Part 1: Comparison of pyrolysis lignin with Klason lignin. J Anal Appl Pyrol. 2006;76:209-13. https://doi.org/10.1016/j.jaap.2005.11.004.

48. Mendez FJ, Bastardo-Gonzalez E, Betancourt P, Paiva L, Brito JL. NiMo/MCM41 Catalysts for the Hydrotreatment of Polychlorinated Biphenyls. Catalysis 
49. Lup ANK, Abnisa F, Daud WMAW, Aroua MK. Synergistic interaction of metalacid sites for phenol hydrodeoxygenation over bifunctional $\mathrm{Ag} / \mathrm{TiO}{ }_{2}$ nanocatalyst. 
657 Table 1 Physical properties and acid strength of synthesized catalysts.

\begin{tabular}{|c|c|c|c|c|c|c|c|c|c|}
\hline \multirow[t]{3}{*}{ Catalyst } & \multirow{3}{*}{$\begin{array}{l}\mathrm{S}_{\mathrm{BET}} \\
\left(\mathrm{m}^{2} \mathrm{~g}^{-1}\right)\end{array}$} & \multirow{3}{*}{$\begin{array}{l}V_{\text {pore }} \\
\left(\mathrm{cm}^{3}\right. \\
\left.\mathrm{g}^{-1}\right)\end{array}$} & \multirow{3}{*}{$\begin{array}{l}S_{\text {pore }} \\
(\AA)\end{array}$} & \multirow{3}{*}{$\begin{array}{l}\mathrm{Ti}^{\mathrm{a}} \\
(\mathrm{wt} \%)\end{array}$} & \multirow{3}{*}{$\begin{array}{l}\mathrm{W}^{\mathrm{a}} \\
(\mathrm{wt} \%)\end{array}$} & \multicolumn{4}{|c|}{ Acidity (mmol NH $\mathrm{g}^{-1}$ catalyst) } \\
\hline & & & & & & Total $^{\mathrm{c}}$ & Weak $^{b}$ & Medium $^{b}$ & Strong ${ }^{b}$ \\
\hline & & & & & & & & & \\
\hline $\mathrm{SiO}_{2}-\mathrm{NC}$ & 28.1 & 0.07 & 42.1 & - & - & - & - & - & - \\
\hline \multirow[t]{2}{*}{$\mathrm{SiO}_{2}-\mathrm{C}$} & 654.2 & 0.52 & 32.0 & - & - & 0.170 & 0.151 & 0.012 & 0.007 \\
\hline & & & & & & & $(88.8 \%)$ & $(7.1 \%)$ & $(4.1 \%)$ \\
\hline \multirow[t]{2}{*}{$\mathrm{Ti}-\mathrm{SiO}_{2}$} & 375.7 & 0.32 & 31.7 & 2.28 & - & 0.339 & 0.308 & 0.024 & 0.007 \\
\hline & & & & & & & $(90.9 \%)$ & $(7.1 \%)$ & $(2.0 \%)$ \\
\hline \multirow[t]{2}{*}{$\mathrm{W}-\mathrm{SiO}_{2}$} & 413.8 & 0.32 & 30.5 & - & 6.82 & 0.485 & 0.392 & 0.081 & 0.012 \\
\hline & & & & & & & $(80.8 \%)$ & $(16.7 \%)$ & $(2.5 \%)$ \\
\hline
\end{tabular}

$658 \mathrm{~S}_{\mathrm{BET}}-$ the surface area measured by BET method.

$659 \quad \mathrm{~V}_{\text {pore }}$ - the volume of pore.

$660 \quad S_{\text {pore }}-$ the size of pore.

$661{ }^{a}$ Determined by ICP-OES.

$662{ }^{\mathrm{b}}$ Weak, medium, strong acidity $\left(<200{ }^{\circ} \mathrm{C}, \sim 300^{\circ} \mathrm{C},>400{ }^{\circ} \mathrm{C}\right)$.

$663{ }^{\mathrm{c}}$ Determined by $\mathrm{NH}_{3}$-TPD.

664

665

666

667

668 Table 2. Physical properties of spent catalyst and reactivated one. 


\begin{tabular}{|c|c|c|c|c|c|c|c|c|c|}
\hline \multirow[t]{3}{*}{ Catalyst } & $\mathrm{S}_{\mathrm{BET}}$ & $V_{\text {pore }}$ & $S_{\text {pore }}$ & $\mathrm{W}^{\mathrm{a}}$ & $\mathrm{Ni}^{\mathrm{a}}$ & $\mathrm{Mo}^{\mathrm{a}}$ & Lignin & Bio-oil & Char \\
\hline & $\left(\mathrm{m}^{2} \mathrm{~g}^{-1}\right)$ & $\left(\mathrm{cm}^{3} \mathrm{~g}^{-}\right.$ & $(\AA)$ & $(w t \%)$ & $(w t \%)$ & $(w t \%)$ & conversion & $(w t \%)$ & $(w t \%)$ \\
\hline & & \multicolumn{5}{|l|}{$\left.{ }^{1}\right)$} & \multicolumn{3}{|l|}{$(w t \%)$} \\
\hline Fresh & 325.8 & 0.27 & 30.1 & 6.82 & 28.5 & 40.1 & 66.3 & 57.2 & 9.1 \\
\hline Reuse-1 & 273.4 & 0.18 & 35.2 & 6.64 & 27.3 & 39.4 & 62.1 & 52.9 & 9.2 \\
\hline Reuse-2 & 241.2 & 0.16 & 37.1 & 6.55 & 27.1 & 39.1 & 60.3 & 51.6 & 8.7 \\
\hline Reuse-3 & 218.3 & 0.15 & 35.6 & 6.52 & 26.4 & 39.0 & 58.3 & 49.8 & 8.5 \\
\hline Reuse-4 & 211.2 & 0.17 & 34.9 & 6.44 & 26.1 & 38.5 & 54.9 & 46.7 & 8.2 \\
\hline Reuse-5 & 211.4 & 0.12 & 37.2 & 6.38 & 26.1 & 37.8 & 52.5 & 44.4 & 8.1 \\
\hline Reactivation & 321.2 & 0.26 & 30.2 & 6.33 & 25.3 & 37.4 & 63.2 & 54.2 & 9.0 \\
\hline
\end{tabular}

${ }^{a}$ Determined by ICP-OES.

670

671

672

673

674

675

676

677

678

679

680 Table 3. Proximate, ultimate, and component analyses of raw and extracted lignin. 


\begin{tabular}{|c|c|c|c|c|c|c|c|c|c|}
\hline \multirow[t]{3}{*}{ Sample } & \multicolumn{4}{|c|}{ Proximate analysis ${ }^{\mathrm{a}}(\mathrm{wt} \%)$} & \multicolumn{4}{|c|}{ Ultimate analysis ${ }^{\mathrm{c}}(\mathrm{wt} \%)$} & \multirow{2}{*}{$\begin{array}{l}\text { Lignin } \\
\text { content }{ }^{\mathrm{d}} \text {, }\end{array}$} \\
\hline & \multirow[t]{2}{*}{ Moisture } & \multirow[t]{2}{*}{ Ash } & Volatile & Fixed & $\mathrm{C}$ & $\mathrm{H}$ & $\mathrm{O}^{\mathrm{b}}$ & $\mathrm{N}$ & \\
\hline & & & matter & carbon $^{\mathrm{b}}$ & & & & & $(w t \%)$ \\
\hline Raw lignin & 5.6 & 2.7 & 71.5 & 20.2 & 46.7 & 7.1 & 45.3 & 0.9 & 80.2 \\
\hline Extracted & 4.9 & 2.5 & 74.3 & 18.3 & 47.4 & 7.3 & 44.7 & 0.6 & 98.8 \\
\hline lignin & & & & & & & & & \\
\hline
\end{tabular}

$681{ }^{a}$ Measured by ASTM Standard Test Method E. 1690-01.

$682 \quad{ }^{\mathrm{b}}$ Calculated by difference.

$683{ }^{c}$ Ash and moisture free.

$684{ }^{d}$ On dry basis.

$685{ }^{e}$ Determined by Klason method [47]. 


\section{Figures}
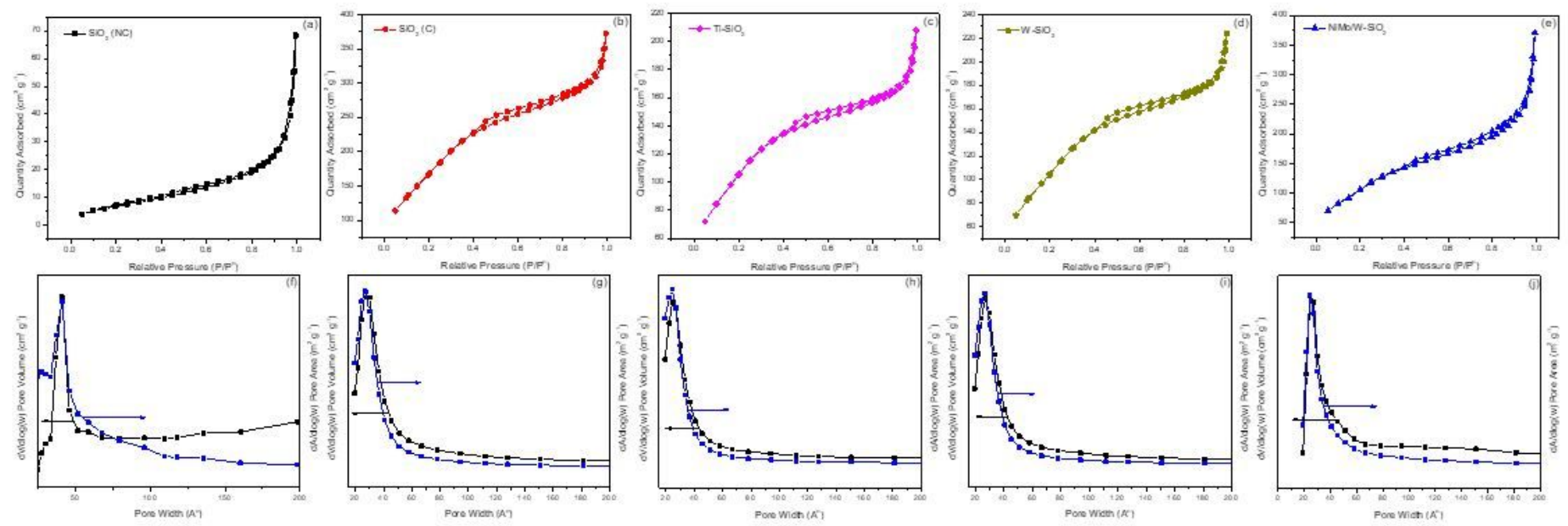

\section{Figure 1}

$\mathrm{N} 2$ adsorption-desorption isotherms of SiO2-NC (a, uncalcined), SiO2-C (b, calcined), Ti-SiO2 (c), W-SiO2 (d), and NiMo/W-SiO2 (e). Respective pore size distributions of different samples (f: SiO2-NC, g: SiO2-C, h: Ti-SiO2, i: W-SiO2, and j: NiMo/W-SiO2).
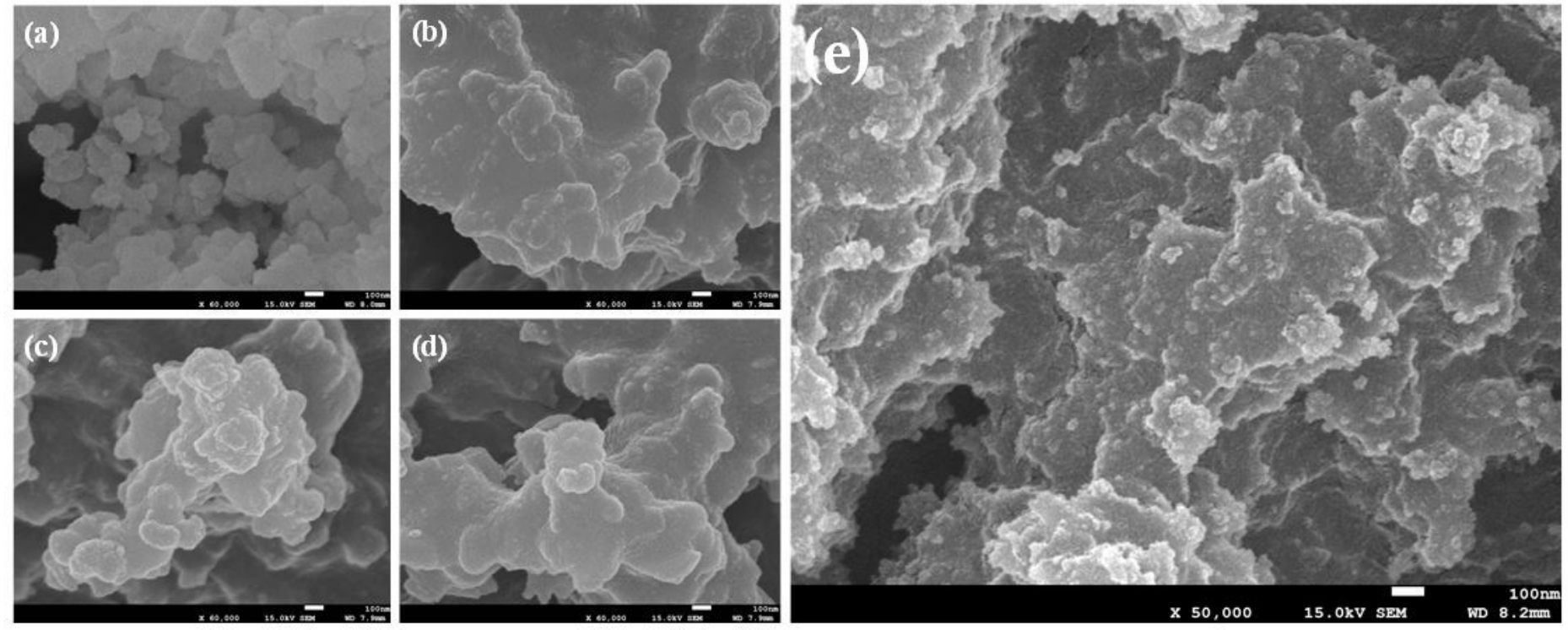

$x 50,000$

\section{Figure 2}

SEM images of SiO2-NC (a), SiO2-C (b), Ti-SiO2 (c), W-SiO2 (d), and NiMo/W-SiO2 (e). 


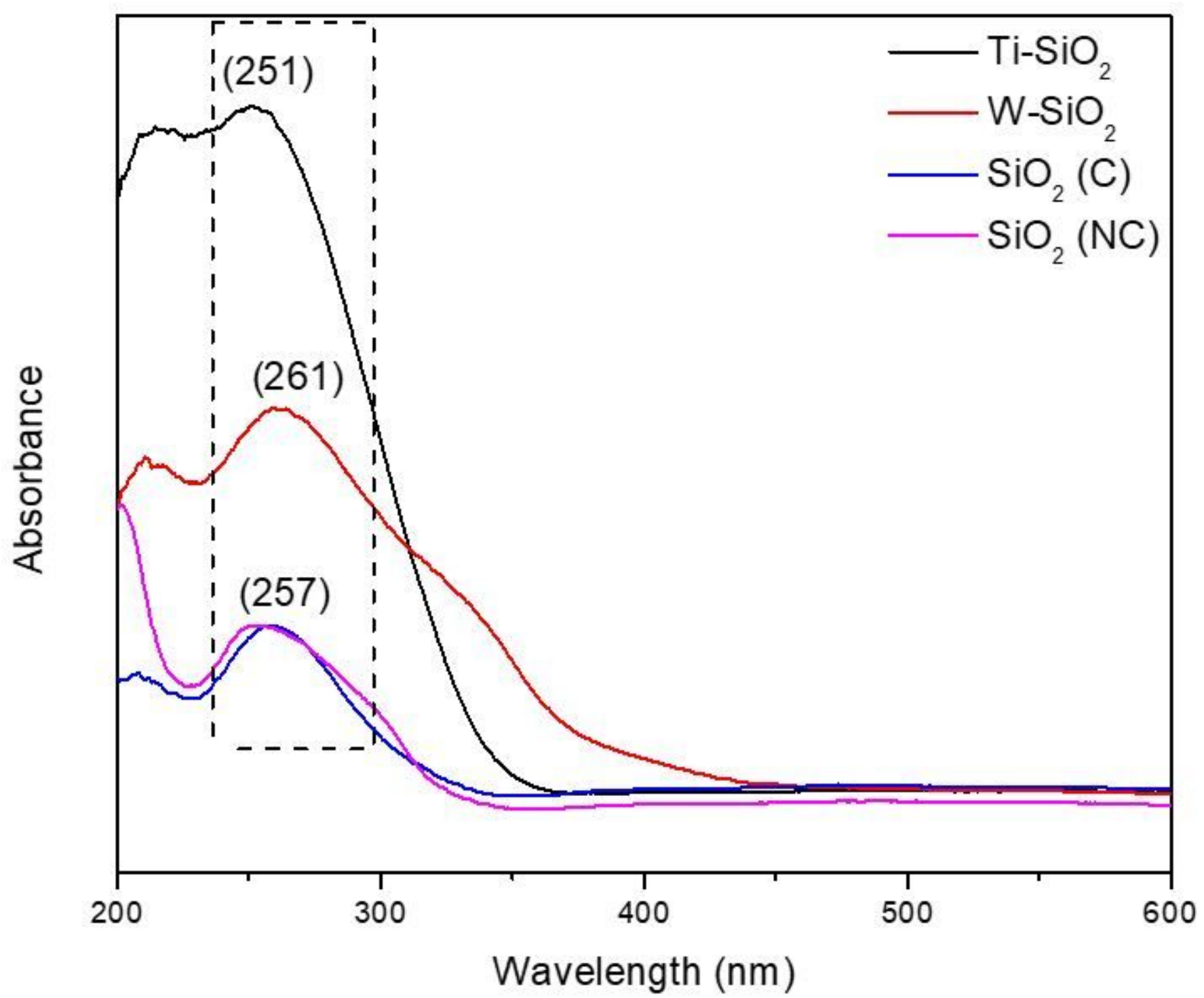

Figure 3

UV-visible diffuse reflectance spectra (DRS) of supports. 


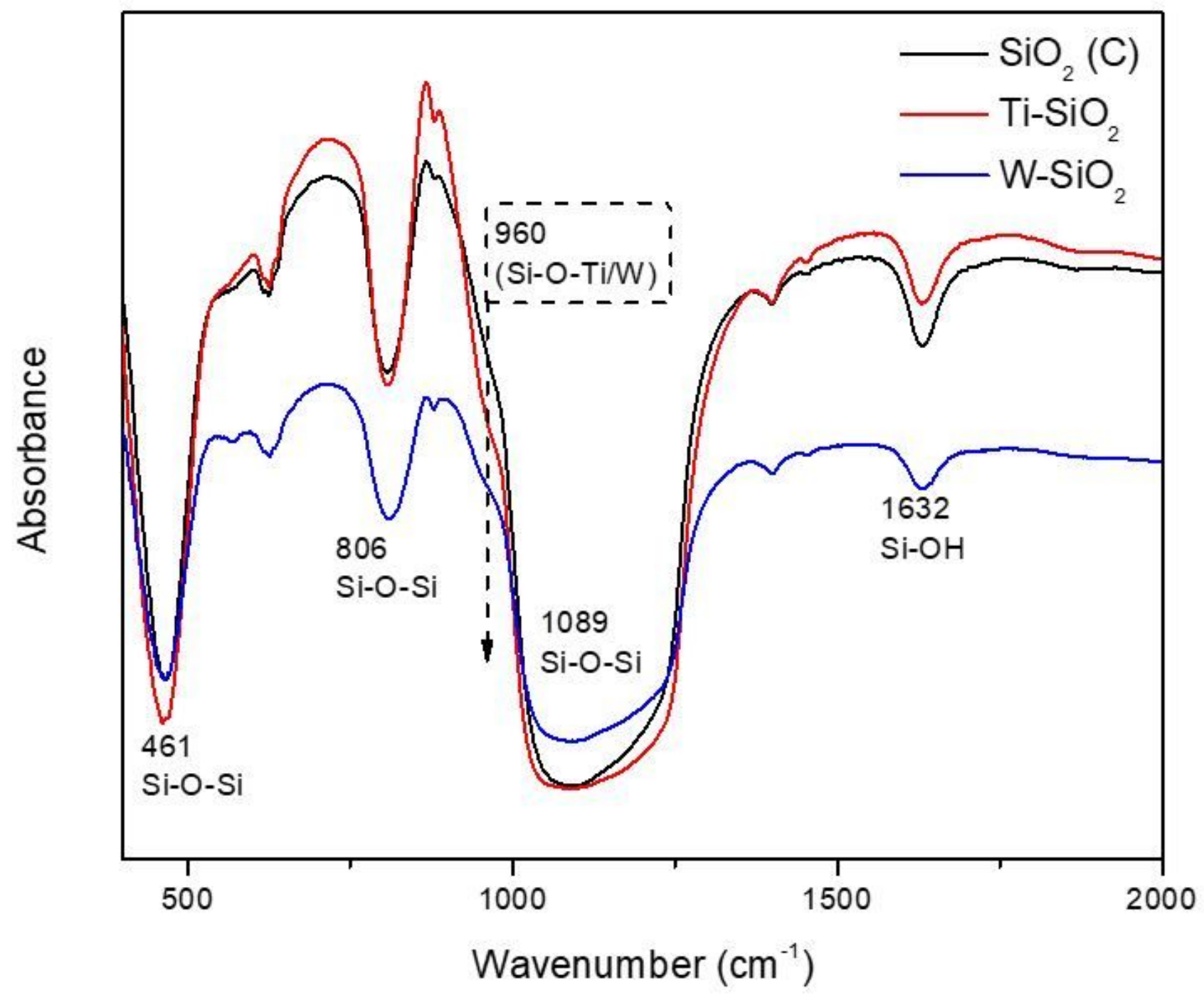

Figure 4

FTIR spectra of synthesized supports. 


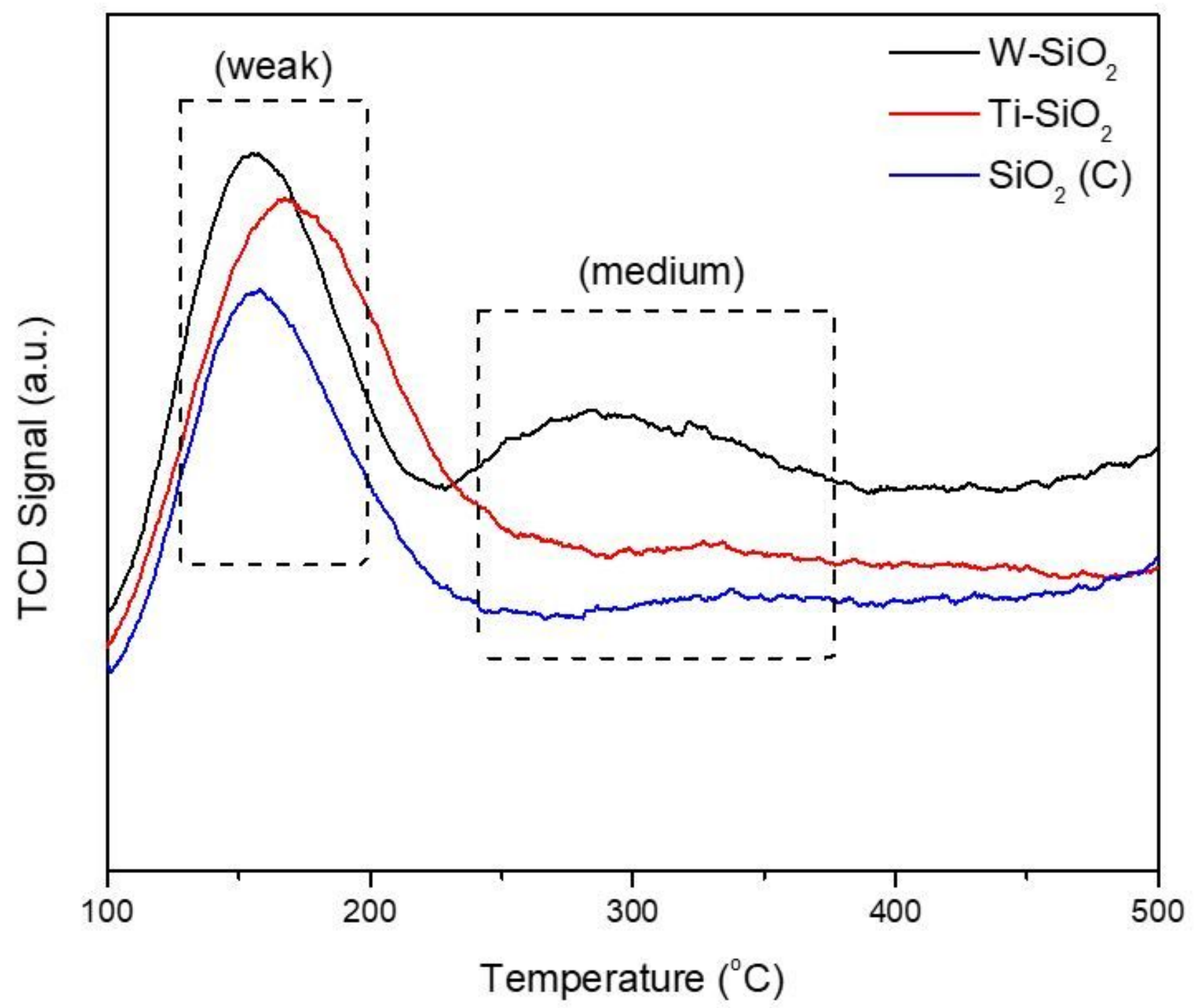

Figure 5

NH3-TPD of SiO2-C (blue line), Ti-SiO2 (red line), and W-SiO2 (black line). 

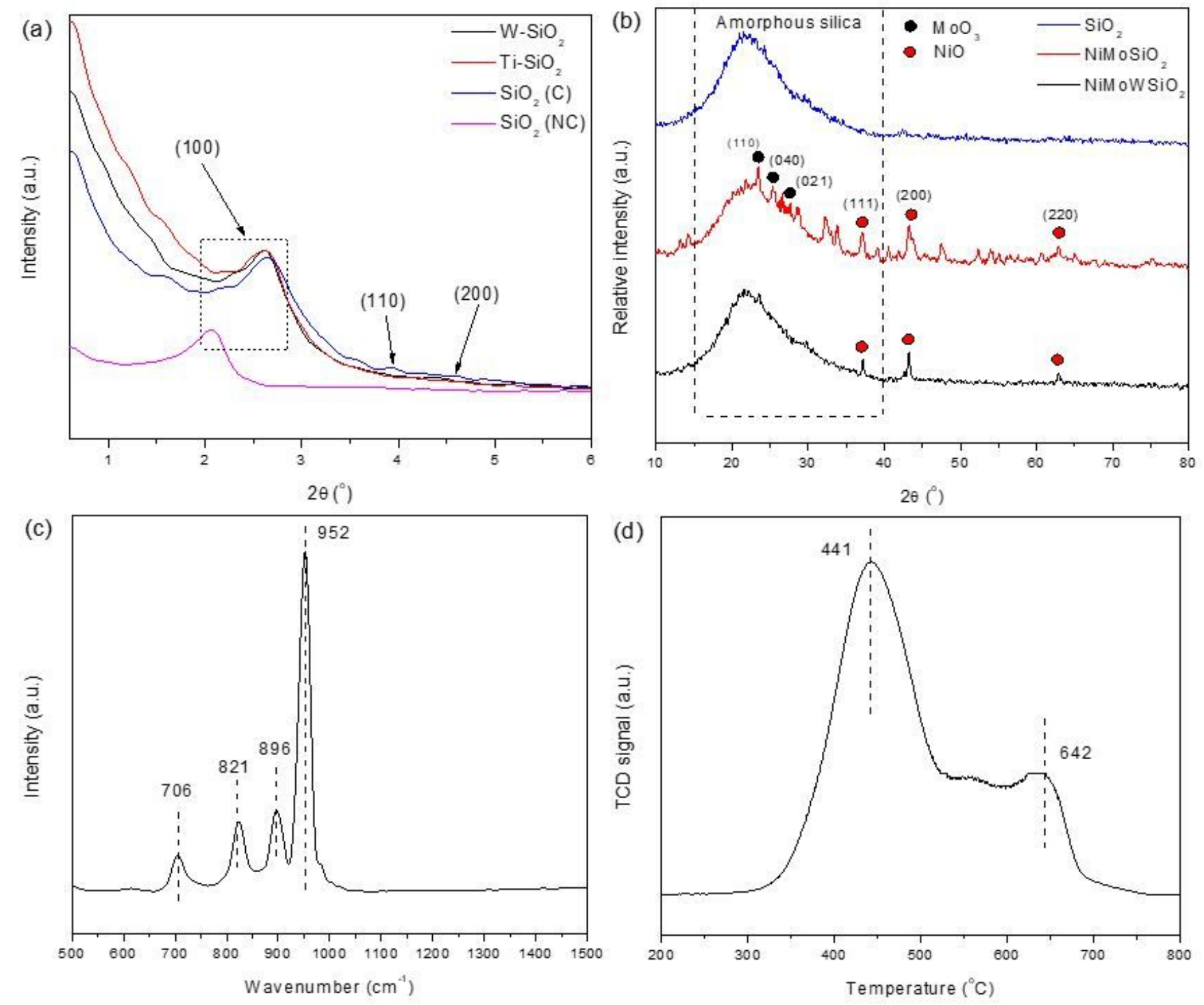

Figure 6

(a) SA-XRD patterns of support and catalysts, (b) WA-XRD patterns of support and NiMo supported catalysts, (c) Raman spectrum of NiMo/W-SiO2, and (d) H2-TPR profile of NiMo/W-SiO2. 


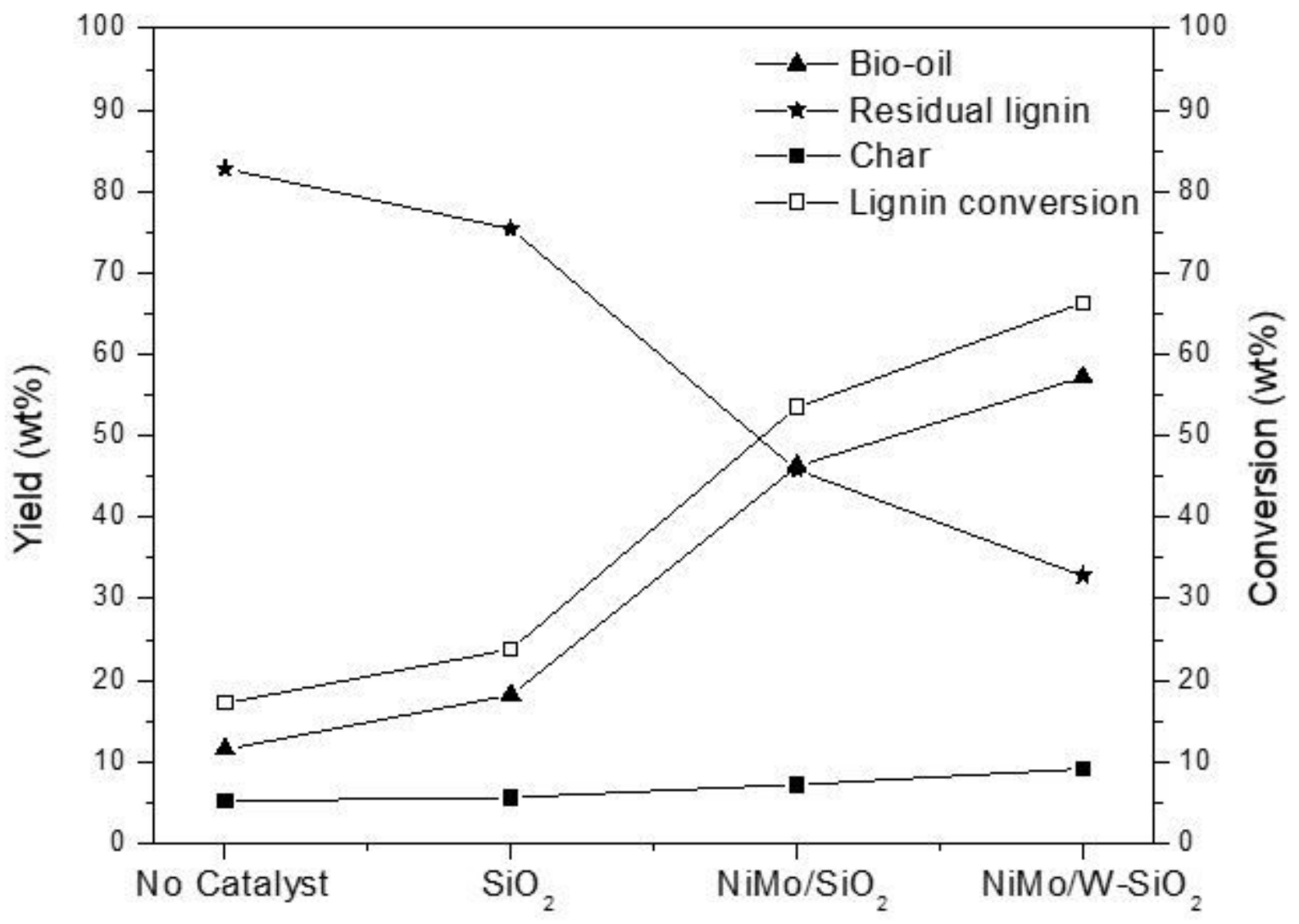

Figure 7

Catalytic evaluation of lignin depolymerization over different synthesized catalysts. 


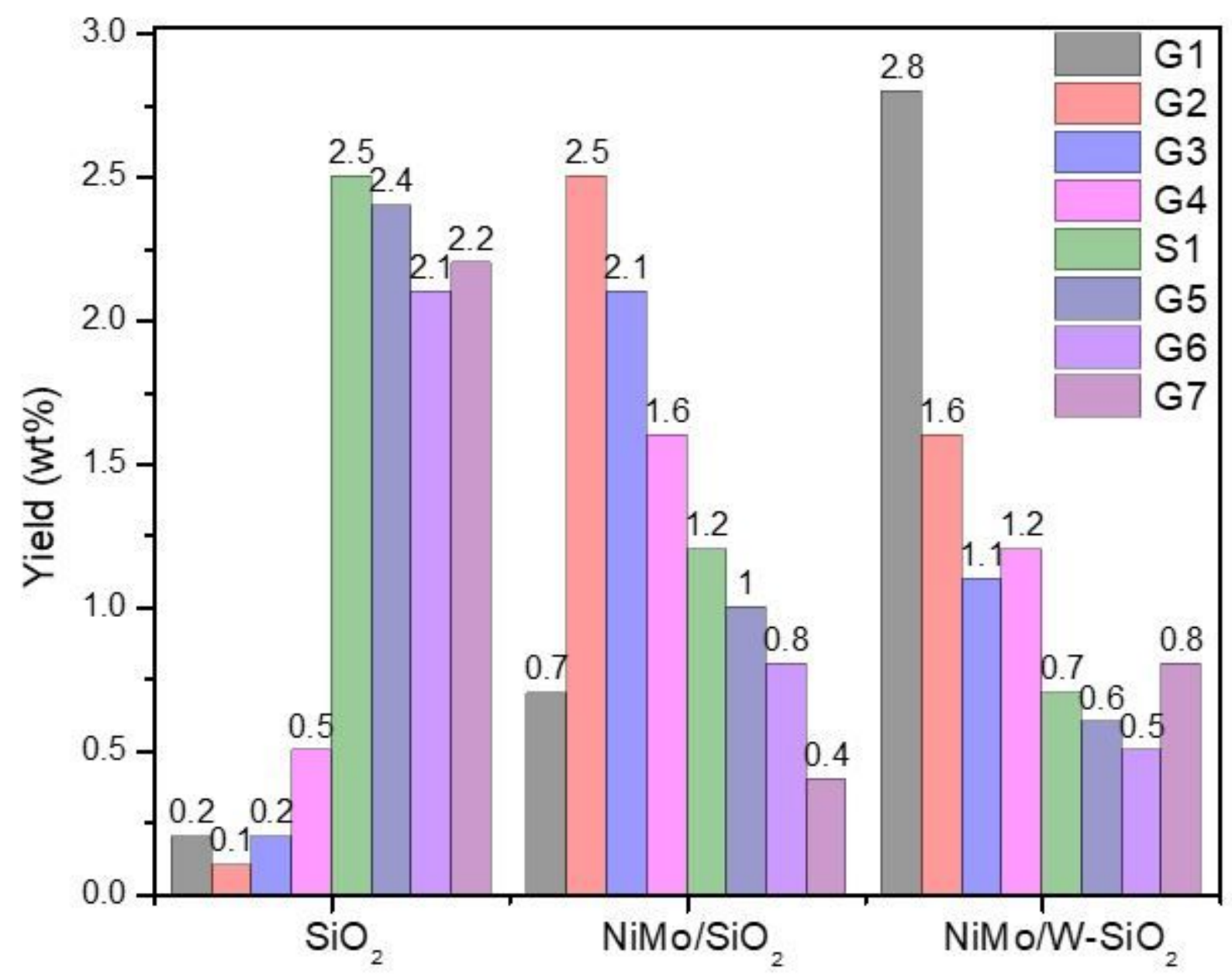

Figure 8

The main monomers (wt\%) produced from lignin depolymerization over NiMo/W-SiO2 (G1: guaiacol, G2: 2-methoxy-4-methylphenol, G3: 4-ethylguaiacol, G4: 2-methoxy-4-(1-propyl)phenol, S1: 2,6dimethoxyphenol, G5: vanillin, G6: 4-hydroxy-3-methoxyacetophenone, G7: 4-hydroxy-3methoxypropiophenone). 


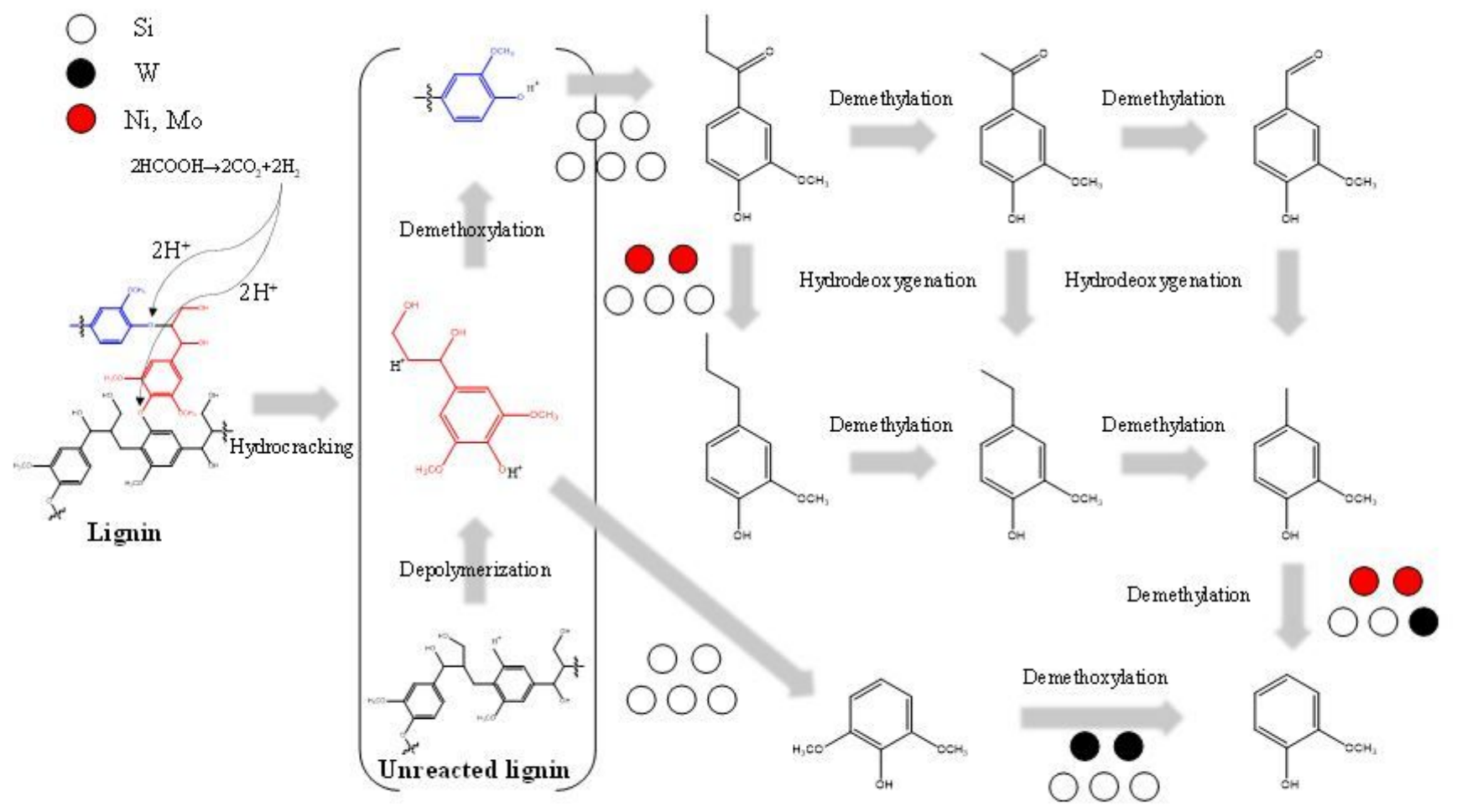

Figure 9

Possible reaction mechanism of lignin depolymerization over supported metal catalysts with assistance of formic acid used as an internal hydrogen donor.

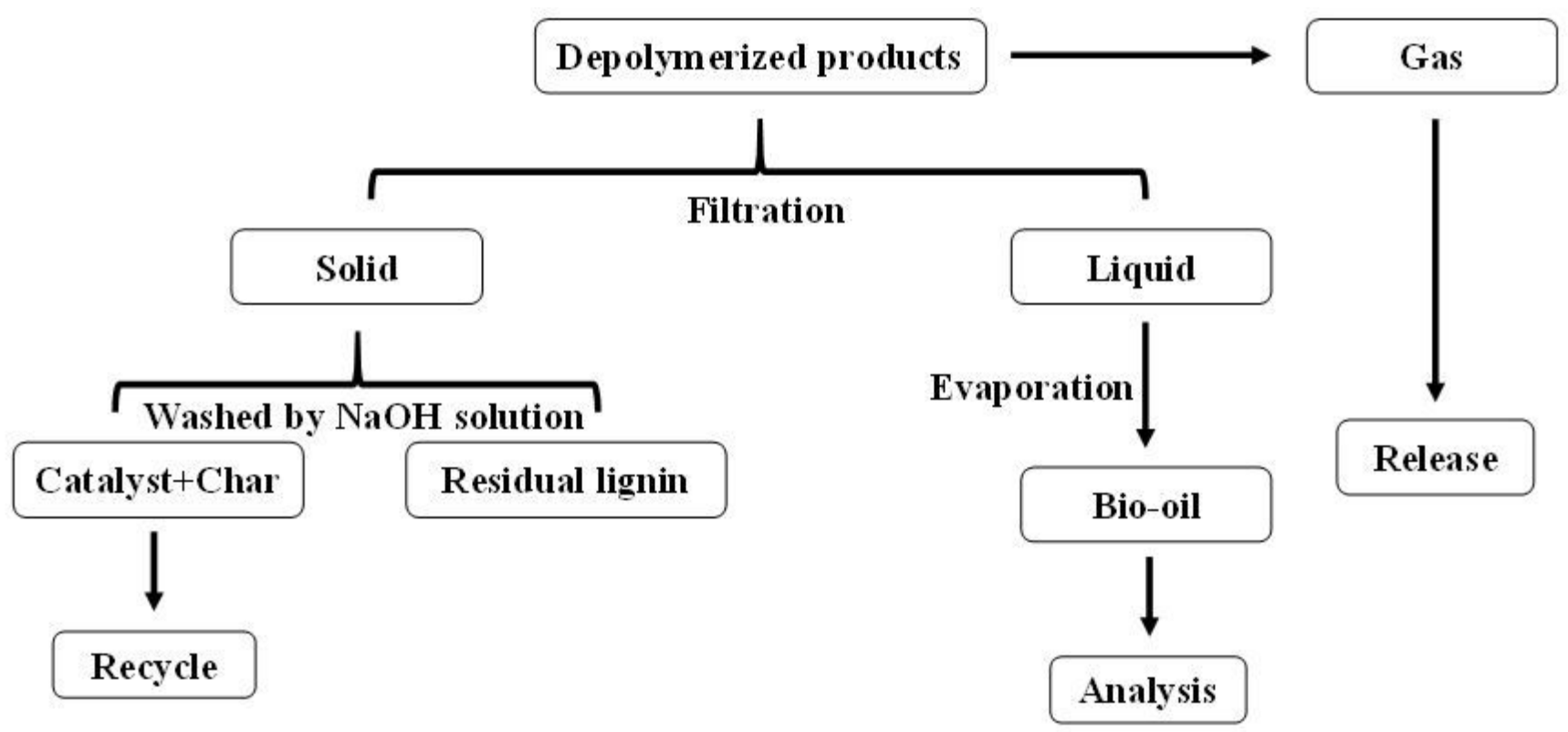

Figure 10

Separation steps of depolymerized phases. 